ISSN: 0514-7336

DOI: http://dx.doi.org/10.14201/zephyrus2013721538

\title{
EL FINAL DEL SOLUTRENSE EN EL ORIENTE CANTÁBRICO A TRAVÉS DE LAS OCUPACIONES DE LA CUEVA DE ARLANPE (LEMOA, VIZCAYA)
}

\section{The end of Solutrean in Cantabrian East region through the Arlanpe Cave occupations (Lemoa, Biscay)}

Joseba Rios-Garaizar*, Diego Garate Maidagan**, Asier Gómez Olivencia***, Diego Arceredillo Alonso****, Eneko Iriarte Avilés*****, Alejandro García Moreno******, Daniel Garrido PimenTEL T****** y Ziortza SAN PEDRO CALLEJA $^{* * * * * * * * *}$

* CENIEH. Paseo Sierra de Atapuerca, s/n.09002 Burgos. Correo-e: joseba.rios@cenieh.es

** CREAP Cartailhac-TRACES-UMR 5806, Université de Toulouse-Le Mirail

*** Centro Mixto UCM-ISCIII. Avda. Monforte de Lemos, 5 (P. 14). 28029 Madrid

**** Dpto. de Ciencias Históricas y Geografía. Edif. I + D + I. Plaza Misael Bañuelos, s/n. UBU. 09001 Burgos

***** Laboratorio de Evolución Humana. Dpto. de Ciencias Históricas y Geografía. Edif. I + D + I. 09001 Burgos

******MONREPOS. Archeological Research Centre and Museum for Human Behavioural Evolution, RGZM.

Schloss Monrepos 56567 Neuwied, (Alemania)

******* Cuevas Prehistóricas de Cantabria. Soc. Reg, de Cultura y Deporte. Pasaje de Peña, 2. 39008 Santander

******* Museo Vasco. Plaza Miguel de Unamuno, 4. 48006 Bilbao

Recepción: 21/11/2012; Revisión: 12/04/2013; Aceptación: 24/06/2013

BIBLID [0514-7336 (2013) LXXII, julio-diciembre; 15-38]

RESUMEN: El yacimiento de Arlanpe, situado en un área estratégica a medio camino entre la costa cantábrica y la Llanada Alavesa, presenta un nivel solutrense (nivel II) datado al final de este periodo, entre 21047 y 19909 cal BP. La industria lítica destaca respecto a otros yacimientos contemporáneos por el uso de materias primas locales de calidad mediocre (lutita), el transporte de sílex desde localidades lejanas situadas al N (Flysch) y al S (Trevińo) del yacimiento, la abundancia de laminillas de dorso y la escasez de utillaje típico solutrense. El nivel es pobre en industria ósea, habiéndose recuperado tanto utillaje doméstico como de caza. Los objetos de adorno son escasos y están poco estandarizados. La fauna recuperada está dominada por animales de roquedo, especialmente Capra pyrenaica y Rupicapra pyrenaica, y aparece intensamente procesada. Las características del conjunto permiten interpretar las ocupaciones como un alto de caza complejo en el que se realizan tareas relacionadas con la preparación de la caza junto a otras actividades de carácter más doméstico.

Los resultados del análisis detallado del conjunto arqueológico del nivel II de Arlanpe nos permiten valorar la naturaleza de los procesos de cambio acaecidos en las sociedades del final del Solutrense y proponer hipótesis que expliquen estas transformaciones.

Palabras clave: Paleolítico. Transición. Dataciones. Industria lítica. Alto de caza. Análisis territorial.

ABSTRACT: Arlanpe Cave site, situated in a strategic halfway between the Cantabrian coast and the Alavese Plateau, yielded a Solutrean level (level II) dated at the end of this period, between 21047 and 
$19909 \mathrm{cal}$ вр. The lithic industry displays some unique characteristics, among which the most striking are the use of poor quality local raw materials (silicified mudstone), the transport of flint from distant locations situated at the North (Flysch) and South (Treviño) of the site, the abundance of backed bladelets and the scarcity of typical Solutrean points. The bone industry is poor, having recovered both domestic and hunting tools. The ornaments are scarce and no standardized. The faunal assemblage is mainly composed by rocky environment animals as Capra pyrenaica or Rupicapra pyrenaica whose bones have been heavily processed. The characteristics of the occupation suggest that Arlanpe served as a complex hunting camp where not only tasks related with hunting but also some domestic activities were carried out.

The results of the archaeological analysis of Arlanpe level II allows us to assess the nature of the processes of change that happened to human groups at the end of Solutrean and propose explanatory hypothesis for it.

Key words: Palaeolithic. Transition. Dating. Lithic Industry. Hunting camp. Territorial analysis.

\section{Introducción}

El final del Solutrense en la Región Cantábrica es un proceso que ha sido abordado en este marco geográfico con relativa intensidad en las últimas décadas (Straus, 1974; Bosselin y Djindjian, 1999; Corchón, 1999; De la Rasilla y Straus, 2004; Aura et al., 2012). Este tema ha recibido menor atención que otros, con los que comparte problemas metodológicos e interpretativos, como la transición entre el Paleolítico medio al superior o el origen de las primeras sociedades campesinas. En la actualidad el debate acerca de este tránsito bascula en torno a distintos ejes entre los que cabe destacar la definición del marco cronológico, la caracterización de las estrategias de gestión del utillaje lítico y óseo, de las manifestaciones simbólicas, de las prácticas de subsistencia y de los modelos de gestión del territorio. Con menor intensidad se ha tratado la comparación con los procesos de cambio que se observan en áreas limítrofes o la interpretación de las causas que provocan esos cambios en el registro arqueológico.

El estudio que presentamos en este artículo se centra en la presentación del nivel II del yacimiento de Arlanpe ${ }^{1}$ atribuido en base a criterios estratigráficos, geocronológicos y tecnotipológicos al

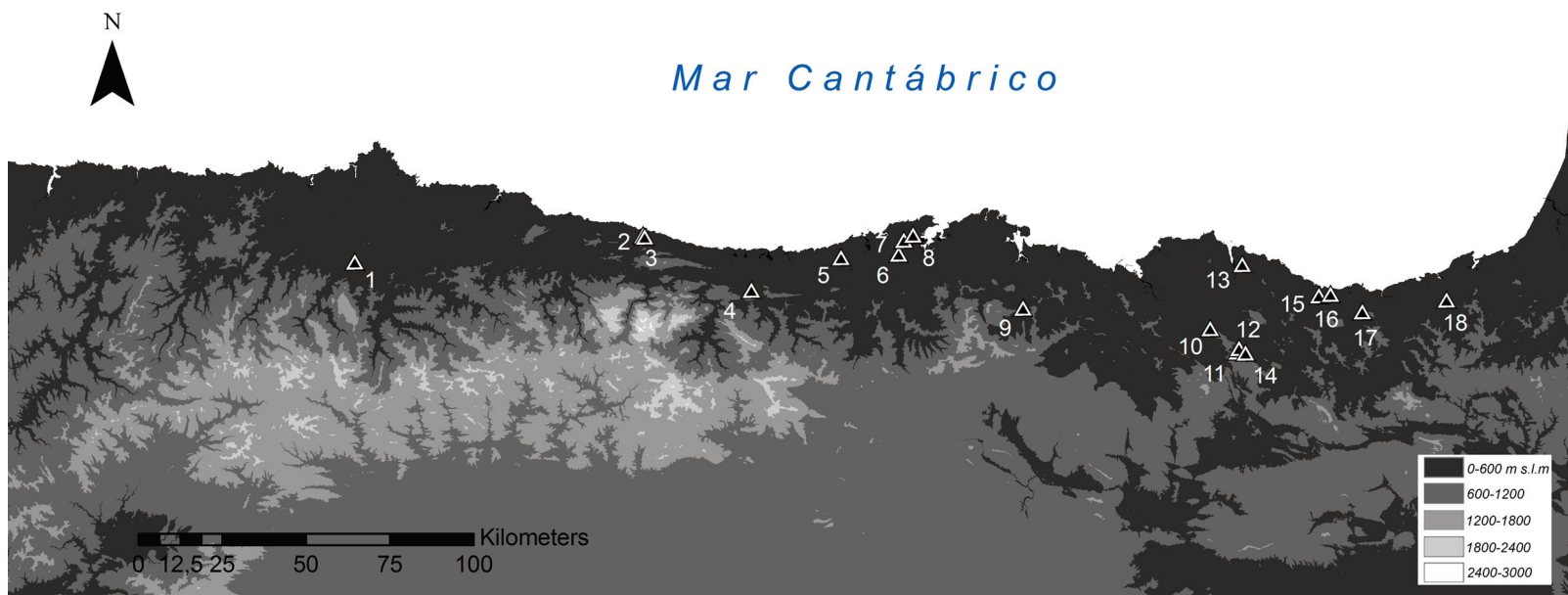

FIG. 1. Mapa de la Cornisa Cantábrica con los principales yacimientos citados en el texto: 1. Las Caldas; 2. Cueto de la Mina; 3. La Riera; 4. Chufin; 5. Altamira; 6. Pendo; 7. Ruso I; 8. Morin; 9. Mirón; 10. Arlanpe; 11. Askondo; 12. Atxuri; 13. Antoliñako Koba; 14. Bolinkoba; 15. Ermittia; 16. Urtiaga; 17. Amalda; 18. Aitzbitarte IV.

${ }^{1}$ Queremos agradecer a la Diput. Foral de Vizcaya, al Gobierno Vasco, a la Fundación Barandiarán, al Ayuntamiento de Lemoa, Eusko Ikaskuntza y a Harpea Kultur Elkartea la colaboración y/o financiación del proyecto de estudio de la cueva de Arlanpe. Gracias también a todas las personas que han participado en la excavación y al resto del equipo de investigación de Arlanpe. AGO ha disfrutado de una beca postdoctoral del Ministerio of Educación (Programa Nacional de Movilidad de Recursos Humanos del Plan Nacional de I+D+I 2008-2011) y recibe apoyo del Ministerio de Ciencia e Innovación (Proyecto CGL2009-12703-C03-03). Queremos agradecer asimismo a la editora de la revista y a los revisores anónimos las sugerencias realizadas. 
Solutrense superior final. Trataremos la cronología de los depósitos, la gestión del utillaje lítico y óseo, las estrategias de subsistencia y la gestión del territorio. Pretendemos con ello aportar datos novedosos para algunos de los debates abiertos y proponer nuevas hipótesis explicativas acerca de los procesos de cambio producidos al final del Solutrense.

\section{Localización geográfica, territorio y geomorfología de la cueva de Arlanpe}

La cueva de Arlanpe se localiza en la ladera O del monte Pagotxueta, en las estribaciones del macizo de Aramotz. Su boca, con orientación NO, se abre a media altura del farallón calizo de Arlanpeko Atxa, sobre el barrio de Landais en el término municipal de Lemoa (UTM 30T; x: 519254 y: 4782262 z: 204). En el entorno de Arlanpe hay otros yacimientos, algunos destruidos por canteras como Atxuri o Atxubita, que presentan indicios de ocupación durante el Paleolítico superior, el primero con evidencias claras de ocupación durante el Solutrense (Gárate, 2012). Cerca de Arlanpe están también el yacimiento Solutrense clásico de Bolinkoba -cf. una síntesis en Gárate, 2012- y
Askondo, que dispone de una fecha de $17490 \pm$ 90 BP para un nivel con escasos indicios de presencia humana (Garate y Rios-Garaizar, 2012).

El entorno del yacimiento es fundamentalmente abrupto (Fig. 2), ya que el $50,52 \%$ del territorio comprendido en un radio de $10 \mathrm{~km}$ alrededor de la cueva presenta una pendiente superior al 30\% de desnivel, mientras que sólo un $4,72 \%$ son tierras llanas -pendiente inferior al $5 \%-$.

Desde la cueva hay buena visibilidad de la confluencia entre los ríos Arratia e Ibaizabal, así como de algunas cimas del entorno de dicha confluencia (Fig. 2). La principal vía de desplazamiento desde el yacimiento es el valle del río Arratia, que, siguiendo un eje norte-sur, permite alcanzar la Llanada Alavesa a través del puerto de Barazar. Un segundo eje de desplazamiento potencial estaría conformado por el valle del río Ibaizabal, que permite un desplazamiento E-O comunicando la costa con el Duranguesado. Partiendo del yacimiento de Arlanpe se puede alcanzar en menos de 2 horas la mayor parte del cauce del río Arratia, así como la cuenca media del Ibaizabal. Desde un punto de vista arqueológico, resulta interesante resaltar el hecho de que el yacimiento de Baltzola se encuentra en el límite de
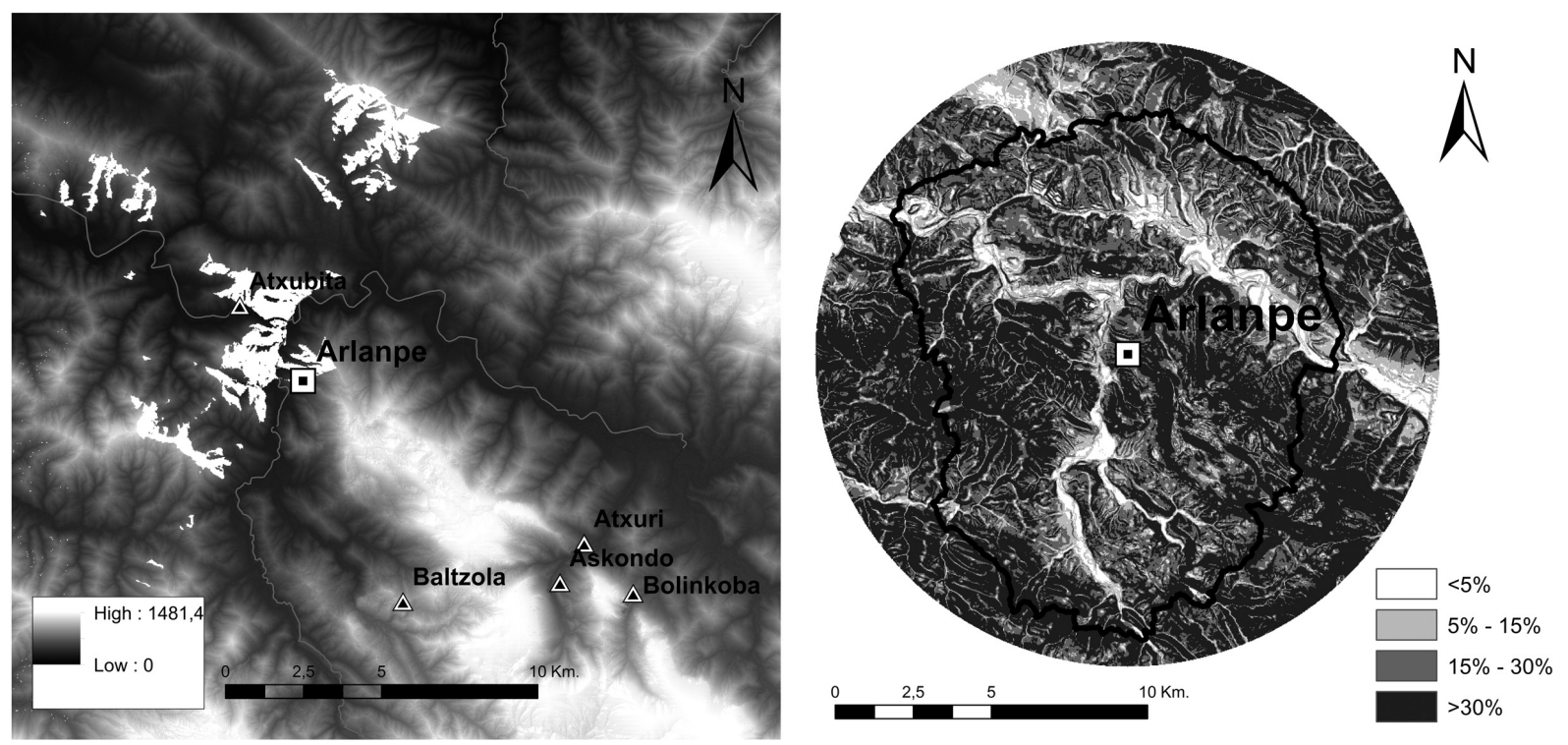

FIG. 2. MDT en el que se observa la posición de Arlanpe respecto a otros yacimientos con ocupaciones del Paleolítico superior. Las áreas blancas son los puntos visibles desde el yacimiento y el gráfico de la derecha marca el cálculo de pendientes. 
dicha isocrona, y por lo tanto sería alcanzable en desplazamientos de aproximadamente dos horas.

La boca de la cueva es de 2 × $3 \mathrm{~m}$ y forma romboidal, abriéndose casi directamente sobre el cantil de roca, del que se separa por una banqueta de apenas un metro de longitud. El desarrollo interior de la cavidad es de $25 \mathrm{~m}$ aproximadamente (Fig. 3), en una sola galería o corredor principal del que parten exiguas gateras laterales a derecha y pequeñas hornacinas colgadas a izquierda. A su vez, dentro del corredor principal, se distinguen tres tramos o salas más espaciosas. Las dimensiones interiores son bastante uniformes, unos $3 \times 4 \mathrm{~m}$ en la primera sala, para ir perdiendo altura y anchura, en menor medida, hacia el fondo. La orientación es de NE-SE hasta medio recorrido donde, en la segunda sala, gira ligeramente hacia el E, sin variar hasta el final del desarrollo de la cavidad.

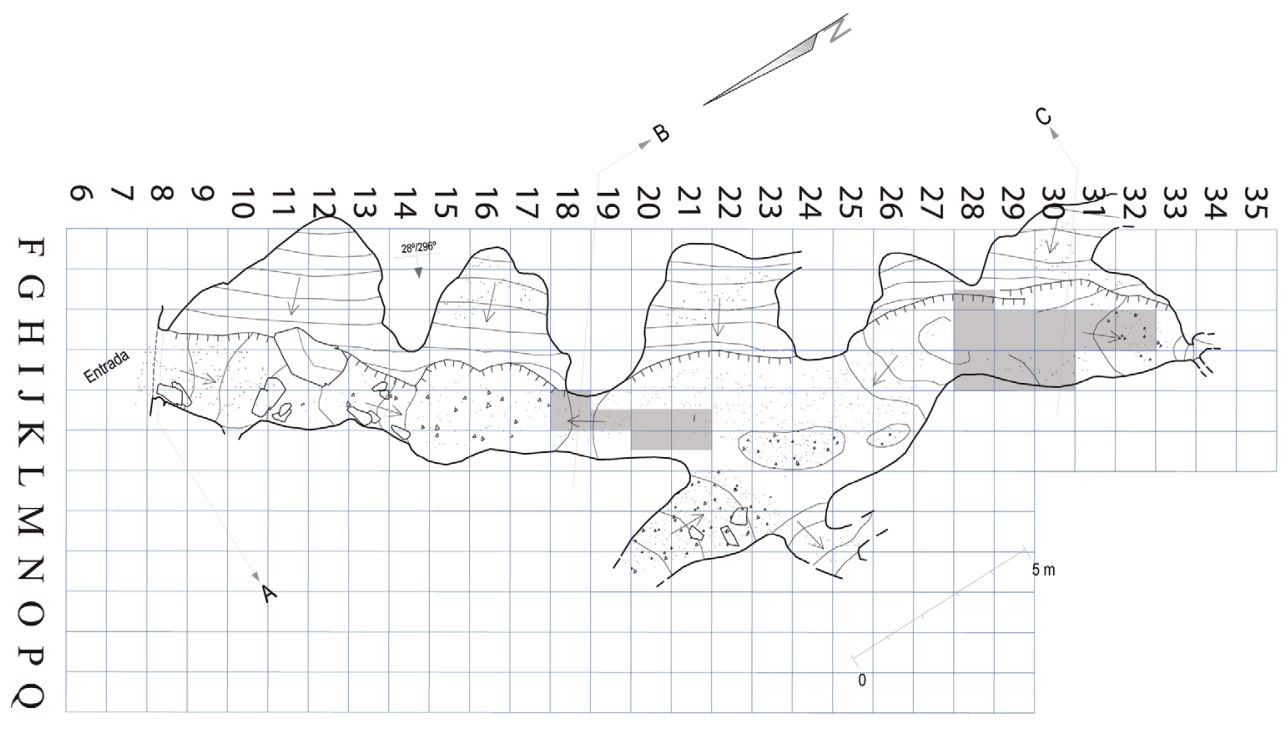

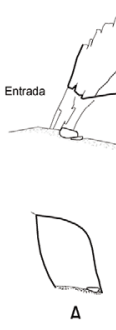

$\prod_{\Delta}$

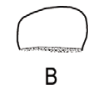

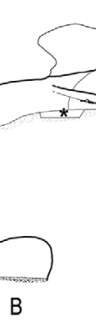

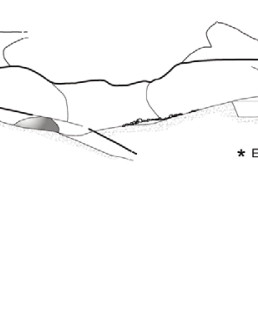

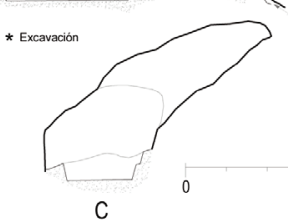

C
FIG. 3.

Planimetría de la cueva de Arlanpe con los sectores excavados entre 2006 y 2010 sombreados en gris.

\section{Historia de las investigaciones}

El yacimiento de la cueva de Arlanpe, descubierto en 1961 por el grupo espeleológico Alegría Club de Amorebieta, ha sido una de las escasas referencias en las que se hacía mención expresa a la existencia de un posible yacimiento del Paleolítico antiguo en Vizcaya (Barandiarán, 1967). No obstante, lo impreciso de la referencia, el paradero desconocido de los materiales y la vaga información disponible sobre la cavidad en general impedían que Arlanpe formase parte del conocimiento prehistórico de Vizcaya más que de manera anecdótica. Desde 2006 se han realizado campañas de excavación en la cavidad en tres sectores diferenciados - "Entrada", "Central” y "Fondo"-. Además de los niveles solutrenses del sector "Entrada", que abordaremos en este trabajo, el yacimiento de Arlanpe destaca por sus ocupaciones del final del Paleolítico inferior (Rios-Garaizar et al., 2011). 
Otros periodos como el Paleolítico superior inicial, el Magdaleniense medio, la Edad del Bronce o la Tardoantigüedad están también representados en la estratigrafía del yacimiento.

\section{Estratigrafía del sector "Entrada"}

Las ocupaciones solutrenses se han detectado en el sector "Entrada". Este se localiza a $10 \mathrm{~m}$ de la boca, en el interior de la cavidad, una vez superado un vestíbulo inicial en el que el suelo se encuentra rebajado artificialmente, quizás por su vaciado parcial en época histórica.

En este sector se ha documentado una secuencia, de algo más de $1,50 \mathrm{~m}$ de desarrollo (Fig. 4), excavada en el sondeo de 2006 (Rios-Garaizar et al., 2008) y en las campañas de 2008-2010. La excavación se desarrolló por cuadrantes de 50 x 50 $\mathrm{cm}$ mediante el sistema de tallas artificiales de 3 a $5 \mathrm{~cm}$ de espesor adaptadas a la realidad estratigráfica. La posición de los restos arqueológicos se

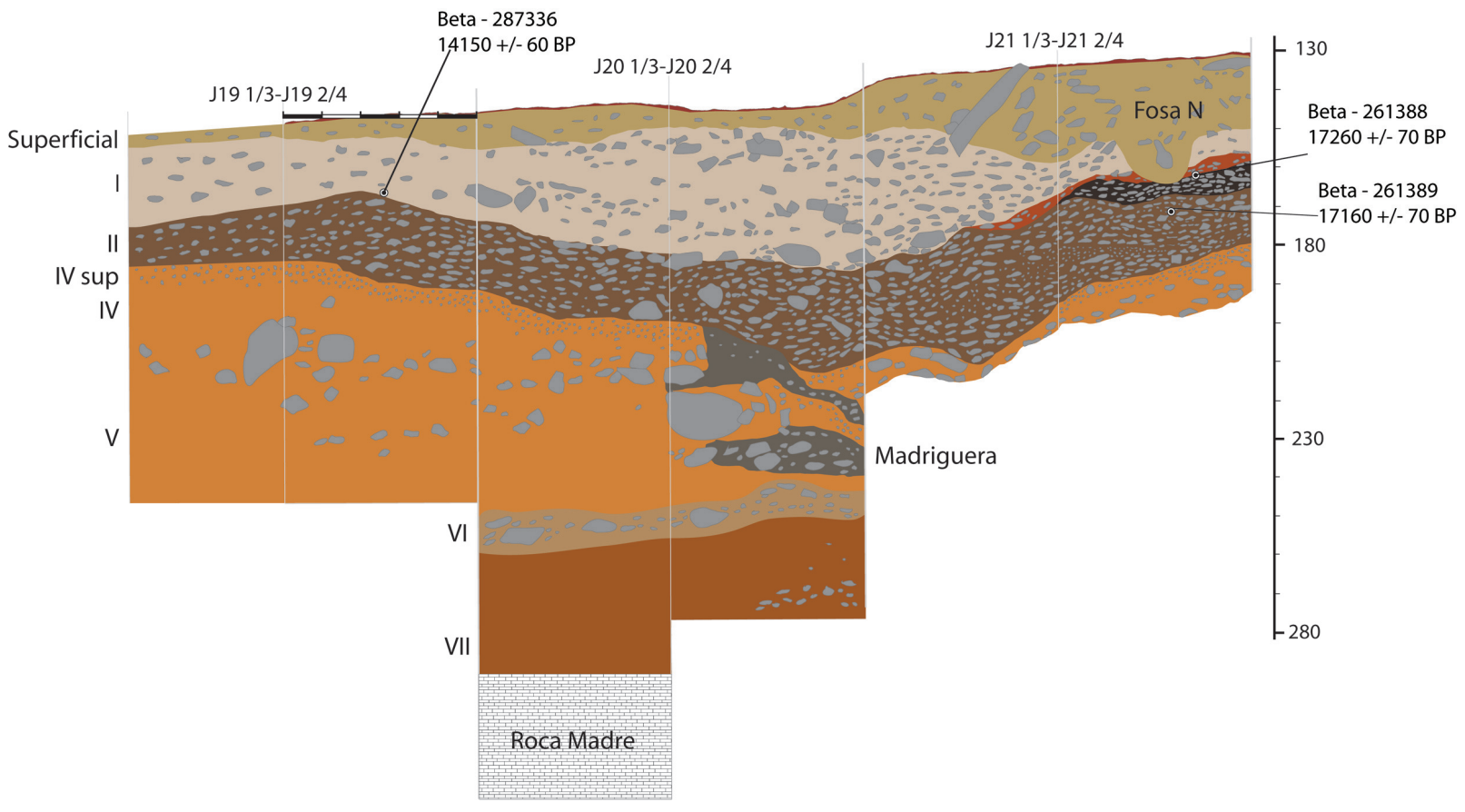

FIG. 4. Corte estratigráfico Oeste del sector de "Entrada".

registró con una estación total topográfica referenciada respecto a un punto cero artificial. Todo el sedimento extraído fue cribado con agua o flotado utilizando para ello mallas de 0,5 y de $1 \mathrm{~mm}$ de luz. Posteriormente, el poso resultante fue tamizado en tres fracciones $(0,5 / 1-2 \mathrm{~mm}, 2-4 \mathrm{~mm},>4$ $\mathrm{mm})$. Las dos más finas se almacenaron para la recuperación de microfauna, pero de la mediana se seleccionaron previamente todos los restos de industria lítica, ósea, ornamentos, etc.; por último, de la mayor se seleccionaron todos los restos arqueológicos y algunos ecofactos significativos.
La estratigrafía se cierra a techo con un nivel superficial de revuelto de entre 10 y $20 \mathrm{~cm}$ que se extiende por toda la superficie y sella los niveles paleolíticos. Estos, a su vez, están revueltos en dos puntos del área excavada debido a sendas fosas antrópicas cuyo relleno arqueológico se compone de restos líticos y óseos de cronología paleolítica mezclados con materiales tardorromanos (Gutiérrez et al., 2012). Por debajo del nivel de revuelto superficial y de las fosas se suceden hasta siete unidades estratigráficas que describimos a continuación: 
- Nivel I: Nivel marrón claro, arcilloso con un contenido moderado en clastos calizos, de un espesor variable de entre 20 y $35 \mathrm{~cm}$, está parcialmente afectado por la excavación de las fosas romanas. El contacto con el nivel subyacente es neto, con un marcado cambio de color y un aumento de los clastos de pequeño tamaño. Este nivel es relativamente rico en materiales paleolíticos atribuidos al Magdaleniense inferior-medio ( $c$. 15100-14100 BP).

- Nivel II: Nivel gris oscuro con abundantes clastos planos de pequeño tamaño combinados con clastos más grandes a techo y a muro del nivel. La disposición de los clastos es planar con un ligero buzamiento hacia la entrada de la cueva. En la base del nivel se ha identificado una capa continua de clastos imbricados sobre la que se deposita el material arqueológico. La dispersión de los restos es homogénea, sin una orientación preferente. Los restos son heterométricos sin que se haya observado una selección por tamaño, de hecho, es significativa la abundancia de microdesechos de talla, incluyendo lasquitas de retoque plano o microlaminillas. En este nivel se han identificado también algunas estructuras, en J21.2 y J21.4 se observa a techo un tramo más oscuro superpuesto por otro rojizo asociado a un hogar sin estructura excavado parcialmente en la esquina NW de J21. En J21.4 y K21.3 se han excavado también una serie de concentraciones carbonosas de unos $30 \mathrm{~cm}$ de diámetro, tratándose de estructuras relacionadas con la estructura de combustión principal, actuando como área de desecho, o pequeñas hogueras desmanteladas. Este nivel tiene una topografía irregular, en algunos puntos está parcialmente cortado por las fosas romanas y en otros puntos se acomoda a las irregularidades de la superficie del nivel subyacente (nivel IV). El espesor medio de este nivel está entre 20 y $30 \mathrm{~cm}$. Se han obtenido dos fechas en el cuadro J21, una (Beta261388) proviene de la parte alta del nivel (z-165) y la otra (Beta-261389) de la parte central del mismo (z: -171). Ambas ofrecen valores semejantes situados en torno a 17100 uncal BP. De este nivel nos ocuparemos en el presente trabajo y su contenido arqueológico será descrito en detalle a continuación.

- Nivel III: La caracterización de este nivel ha sido compleja desde la excavación de 2006. Está formado por un sedimento suelto, de color gris oscuro, con clastos, que forma bolsadas irregulares adaptándose a la topografía del nivel infrayacente. Los materiales que contiene aparecen en ocasiones en posición vertical, sin embargo, la presencia de restos de fauna en conexión anatómica sugiere un escaso desplazamiento desde su posición original. Todo ello nos llevó a plantear la hipótesis de que se trataba del relleno de una fosa excavada en época Solutrense (Rios-Garaizar et al., 2008). En las campañas de 2008-2010 comprobamos que un sedimento semejante rellenaba las madrigueras que atravesaban el nivel IV. Por ello reinterpretamos la "fosa" identificada en 2006 como un relleno con sedimentos del nivel II provocado por el colapso de una madriguera excavada en el nivel IV. Aunque la datación de este nivel y los materiales arqueológicos recuperados en él son coherentes con una atribución al Solutrense superior final, hemos de considerarlo como un conjunto alterado, por lo que vamos a describirlo de manera somera.

\begin{tabular}{|c|c|l|l|l|c|}
\hline Nivel & Método & Muestra & \multicolumn{1}{|c|}{ N. } & UNCAL BP & $\begin{array}{c}\text { CAL BP } \\
(95,4 \%)\end{array}$ \\
\hline II & 14C AMS & Hueso & Beta-261388 & $17260 \pm 70$ & $21047-20201$ \\
\hline II & 14C AMS & Hueso & Beta-261389 & $17160 \pm 70$ & $20939-20114$ \\
\hline III & 14C AMS & Hueso & Beta-238178 & $17070 \pm 80^{2}$ & $20507-19909$ \\
\hline
\end{tabular}

1 Curva de calibración: IntCal 09 (Reimer et al., 2009)

2 Esta datación se publicó como $17060 \pm 80$ en Rios-Garaizar et al. (2008) y se trata de un error de transcripción.

FIG. 5. Dataciones radiométricas de los niveles del Paleolitico superior de Arlanpe.
- Nivel IV: Nivel arcilloso anaranjado, a techo aparecen abundante grava y clastos pequeños semejantes a los del nivel II, aunque con un cambio neto de coloración. A muro aparecen grandes fragmentos de costra $(15-20 \mathrm{~cm})$ y el 
sedimento cambia ligeramente de color, a pesar de lo cual la separación con el nivel V no es neta. El sedimento del nivel IV está atravesado en numerosos puntos por madrigueras, cuya extensión es fácilmente identificable por el color oscuro de su relleno. Este nivel se ha atribuido al Paleolítico antiguo -inferior o medio-.

- Nivel v: Nivel ligeramente más anaranjado que el anterior que se desarrolla en unos 20-30 $\mathrm{cm}$ de espesor por debajo del lecho de costra fragmentada. Este nivel está también atravesado por canales de madrigueras. La densidad de materiales arqueológicos es menor que la anterior.
- Nivel VI: A muro del nivel V se desarrolla un nivel de unos 10-20 cm, de color marrón oscuro, con clastos calizos, fragmentos de costra, carbones y conchas de caracol terrestre. Los materiales líticos recuperados permiten una adscripción al Paleolítico antiguo.

- Nivel VII: Nivel arenoso de fuerte color anaranjado. En su interior hay abundantes nódulos ferruginosos y cantos rodados de arenisca. Este nivel descansa directamente sobre la roca madre y es prácticamente estéril desde un punto de vista arqueopaleontológico.

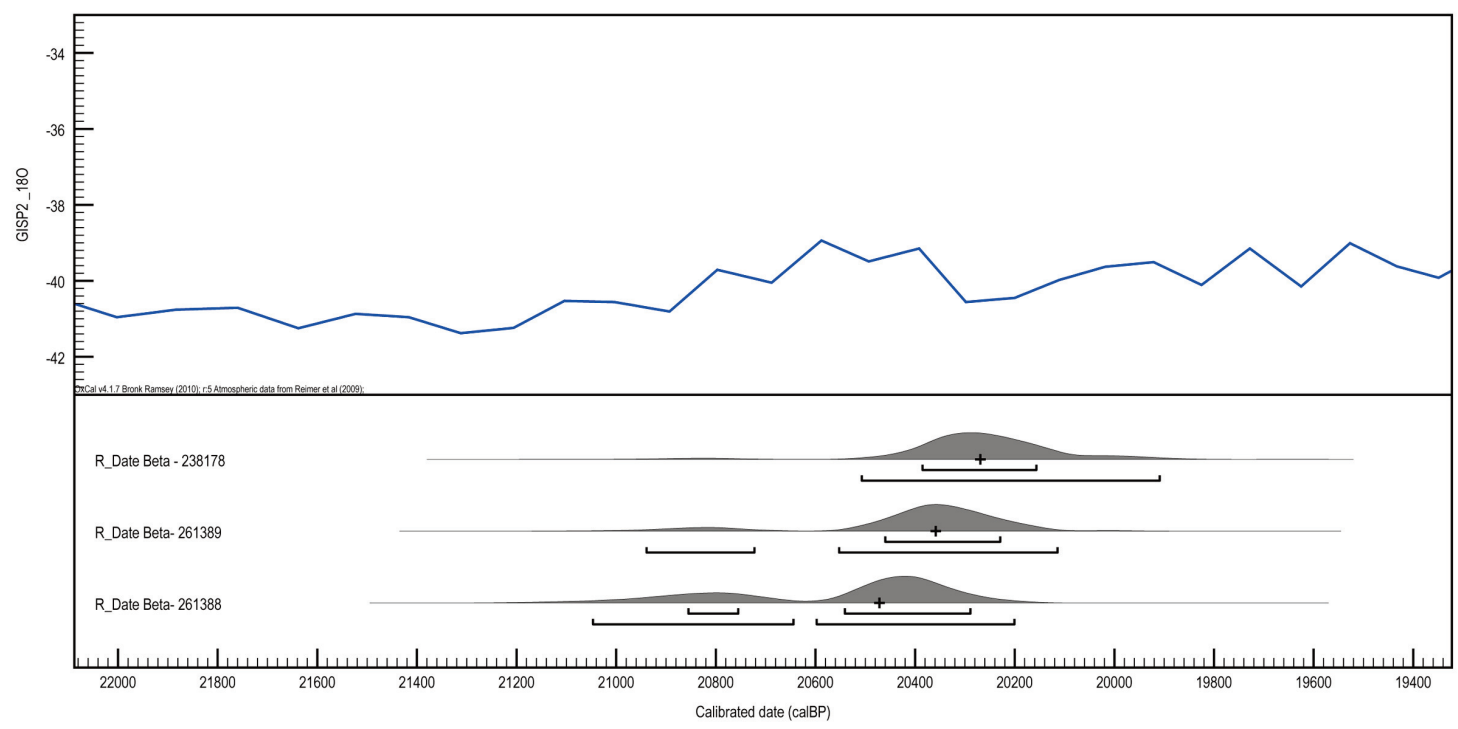

FIG. 6. Dataciones calibradas de los niveles II y III. La curva GISP2 se muestra sólo con el objetivo de relacionar las dataciones con cambios climáticos a escala global.

\section{Dataciones radiométricas de los niveles solutrenses de la cueva de Arlanpe}

El programa de dataciones de los niveles solutrenses de Arlanpe mediante $\mathrm{C}^{14}$ AMS ha proporcionado hasta el momento 3 fechas, dos para el nivel II y una para el III (Fig. 5). Estas dataciones han sido realizadas en los laboratorios de BETA analytic en Florida, sobre muestras de hueso recogidas con coordenadas.

Los resultados de los niveles II y III están muy agrupados en torno a 17100 BP -entre 21047 y 19909 cal BP, Fig. 6-. Estas dataciones sitúan las ocupaciones de Arlanpe al final del último máximo glacial (LGM- Last Glacial Maximum, c. $20000 \mathrm{cal} \mathrm{BP})$.

\section{Las ocupaciones solutrenses de la cueva de Arlanpe. Evaluación arqueológica del nivel II}

El nivel II presenta una buena conservación y ofrece un registro arqueológico más abundante y representativo. En total este nivel ha sido excavado en una superficie aproximada de $2,5 \mathrm{~m}^{2}$ y una profundidad media de $20-30 \mathrm{~cm}$. 


\subsection{Industria lítica}

El conjunto lítico recuperado en el nivel II entre 2006 y 2010 está compuesto por un total de 1845 restos, de los cuales 989 son fragmentos informes y esquirlas de pequeño tamaño.

La composición por materias primas está dominada por el sílex $-66,12 \%$ del total-, frente a la lutita $-24,72 \%-$ (Fig. 7 ). Otros materiales como el ocre o la arenisca aparecen en porcentajes cercanos al 3\% y en formatos muy concretos, mientras el cuarzo, la cuarcita, el cristal de roca o la ofita son anecdóticos. Este modelo de aprovisionamiento contrasta profundamente con el modelo general aceptado para el Paleolítico superior en el Cantábrico oriental, en el que el sílex es la materia prima mayoritaria, superando en la mayoría de los casos el $90 \%$ del total.

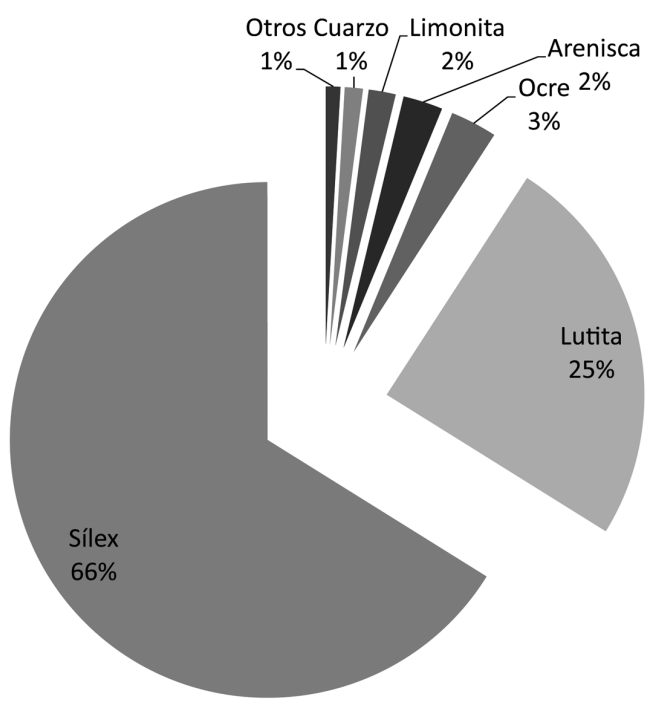

FIG. 7. Porcentajes de materias primas respecto al número de restos del nivel II.
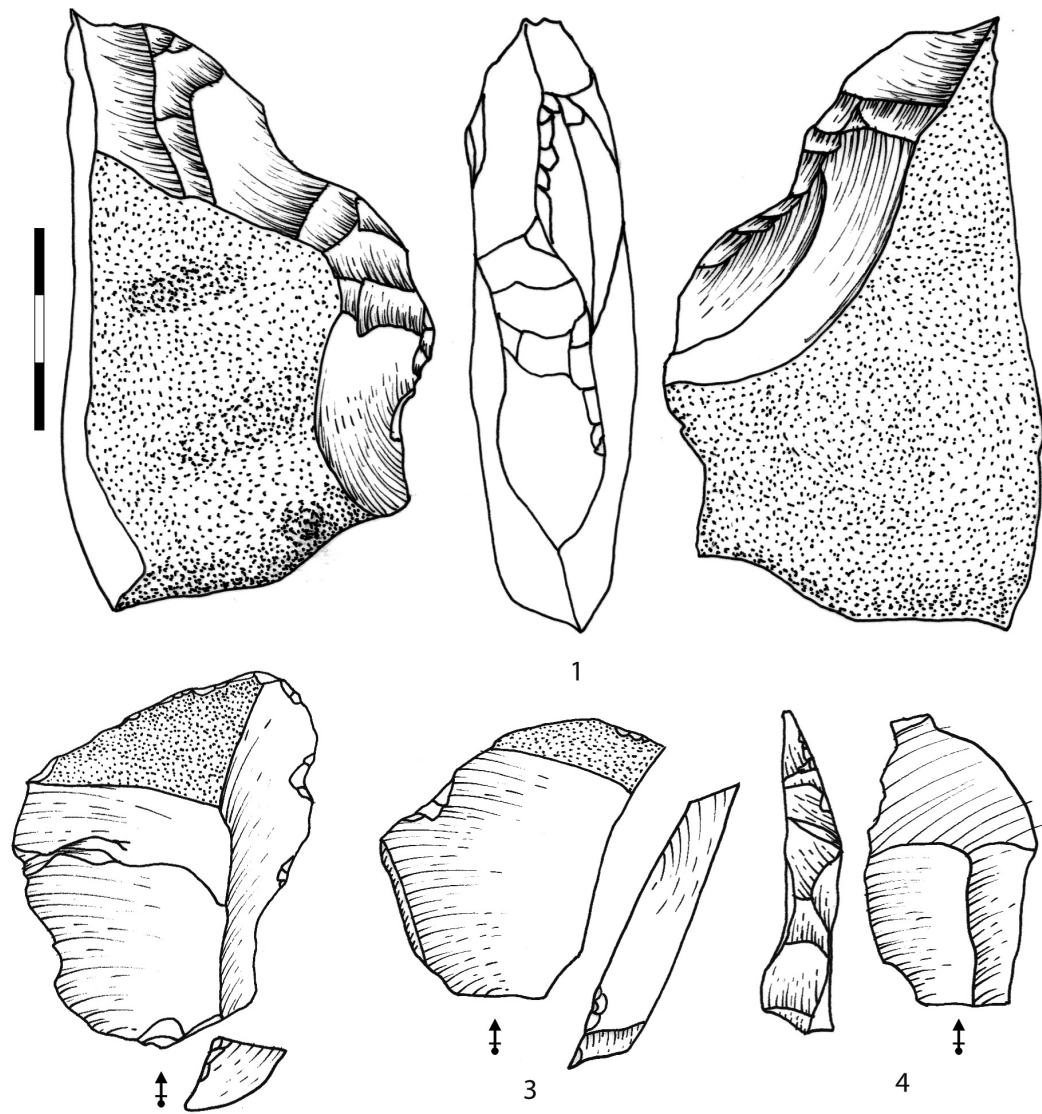

2

FIG. 8. Soportes de lutita del nivel II: 1. macroútil bifacial; 2. lasca cortical; 3. lasca desbordante y 4. lasca Kombewa de 3. a generación.
El aprovisionamiento de la lutita es probablemente local, aprovechándose exclusivamente cantos rodados, tal y como puede deducirse a partir de la lectura de las superficies corticales de los soportes recuperados en el nivel II. En la actualidad, en el cauce del río Arratia, a menos de $500 \mathrm{~m}$ del yacimiento, es posible encontrar cantos rodados de lutita con morfologías variadas. Este tipo de materiales aparece también en otros puntos del cauce del Arratia y del Ibaizabal.

El conjunto lítico de lutita está dominado por lascas corticales o simples, en ocasiones de pequeño tamaño. Hay pocos restos laminares y subproductos de fabricación o avivado de los soportes retocados, lo cual contrasta con la abundancia de fragmentos informes. Hay que destacar también la presencia de cantos de lutita tallados o usados en bruto. 


\begin{tabular}{|c|c|c|c|c|c|c|c|c|c|}
\hline Clasificación tecnológica & OT & $\mathrm{CZ}$ & LI & AR & $\mathbf{O}$ & $\mathbf{L}$ & $S$ & Total & $\%$ \\
\hline Núcleo & & 1 & & & & 1 & 3 & 5 & 0,27 \\
\hline Núcleo laminar & & & & & & & 1 & 1 & 0,05 \\
\hline Núcleo laminar sobre lasca & & & & & & & 4 & 4 & 0,22 \\
\hline Lasca decort. $1 .^{\circ}$ & & & 1 & & & 10 & 3 & 14 & 0,76 \\
\hline Lasca decort. 2. ${ }^{\circ}$ & & 2 & 3 & & & 25 & 16 & 46 & 2,49 \\
\hline Lamina decort. $1 .^{\circ}$ & & & & & & & 3 & 3 & 0,16 \\
\hline Lámina decort. 2. ${ }^{\circ}$ & & & & & & 2 & 15 & 17 & 0,92 \\
\hline Cresta & & & & & & & 3 & 3 & 0,16 \\
\hline Semicresta & & & & & & & 4 & 4 & 0,22 \\
\hline Lámina desbordante & & & & & & 1 & 1 & 2 & 0,11 \\
\hline Lámina sobrepasada & & & & & & & 4 & 4 & 0,22 \\
\hline Lámina reflejada & & & & & & & 2 & 2 & 0,11 \\
\hline Tableta de reavivado & & & & & & & 5 & 5 & 0,27 \\
\hline Lasca limpieza cara de lascado & & & & & & 1 & 7 & 8 & 0,43 \\
\hline Resto de fabricación de foliáceos & 2 & & & 3 & & 38 & 16 & 59 & 3,20 \\
\hline Lasca & & & & & & 13 & 1 & 14 & 0,76 \\
\hline Lasca desbordante & 1 & & & & & 16 & 25 & 42 & 2,28 \\
\hline Microlasca & 2 & & & & & 2 & 40 & 44 & 2,38 \\
\hline Soportes laminares & & & & & & 6 & 237 & 243 & 13,17 \\
\hline Kombewa & & & & & & & 22 & 22 & 1,19 \\
\hline Lasca de reavivado & & & & & & & 61 & 61 & 3,31 \\
\hline Golpe de buril & & & & & & & 11 & 11 & 0,60 \\
\hline Lasca de reavivado bifacial & 1 & & & & & 1 & 90 & 92 & 4,99 \\
\hline Fragmento de esquillada & & & & & & 2 & 4 & 6 & 0,33 \\
\hline Esquirlas y fragmentos informes & 4 & 16 & 1 & & & 329 & 639 & 989 & 53,60 \\
\hline Bloque & 6 & 2 & 25 & 38 & 44 & 4 & 2 & 121 & 6,56 \\
\hline Canto usado & 1 & & 1 & 5 & 10 & 5 & 1 & 23 & 1,25 \\
\hline Total general & 17 & 21 & 31 & 46 & 54 & 456 & 1220 & 1845 & \\
\hline$\%$ Materias primas & 0,92 & 1,14 & 1,68 & 2,49 & 2,93 & 24,72 & 66,12 & & \\
\hline
\end{tabular}

FIG. 9. Composición del total de la industria lítica del nivel II incluyendo soportes retocados y no retocados. Abreviaturas OT: otras; $C Z=$ cuarzo; $L I=$ limonita; $A R=$ arenisca; $O=$ ocre; $L$ : lutita y S: silex.

La explotación de los cantos rodados de lutita se ejecuta para obtener útiles bifaciales de gran tamańo (Fig. 8, n. ${ }^{\circ}$ 1) o para obtener lascas cuadrangulares, en ocasiones de módulo alargado. La sencillez de los sistemas de fabricación se evidencia asimismo en la escasa preparación de los planos de percusión, siendo habituales los talones corticales, los lisos y los diedros asimétricos. El desarrollo de la talla es mayoritariamente unipolar, aunque en ocasiones se sigue un esquema centrípeto de tipo discoide.

La transformación de la lutita en útiles formales es ocasional, no obstante, la abundancia de macrohuellas de uso sugiere que se destina a un uso en bruto. Los útiles retocados entrarían dentro de la categoría de utillaje de sustrato -escotaduras, raederas, denticulados, etc.-. La elección y el uso de esta materia prima se enmarcan dentro de una lógica funcional por la cual esta materia viene a cubrir necesidades inmediatas de útiles de tamaño grande y medio (Fig. 10).

El aprovisionamiento del sílex es más complejo e incluye fundamentalmente variedades obtenidas en Treviño, al sur de la cordillera cantábrica $(-50$ $\mathrm{km}$ ), y sílex del Flysch proveniente de afloramientos de la costa vizcaína: zonas de Barrika $(-28 \mathrm{~km})$ y de Gernika $(-20 \mathrm{~km})$. Otros tipos de sílex, provenientes de afloramientos más lejanos como los de Urbasa $(-60 \mathrm{~km})$ o los sílex translúcidos de Loza $(-55 \mathrm{~km})$ o Monte Picota $(\sim 100 \mathrm{~km})$, son 


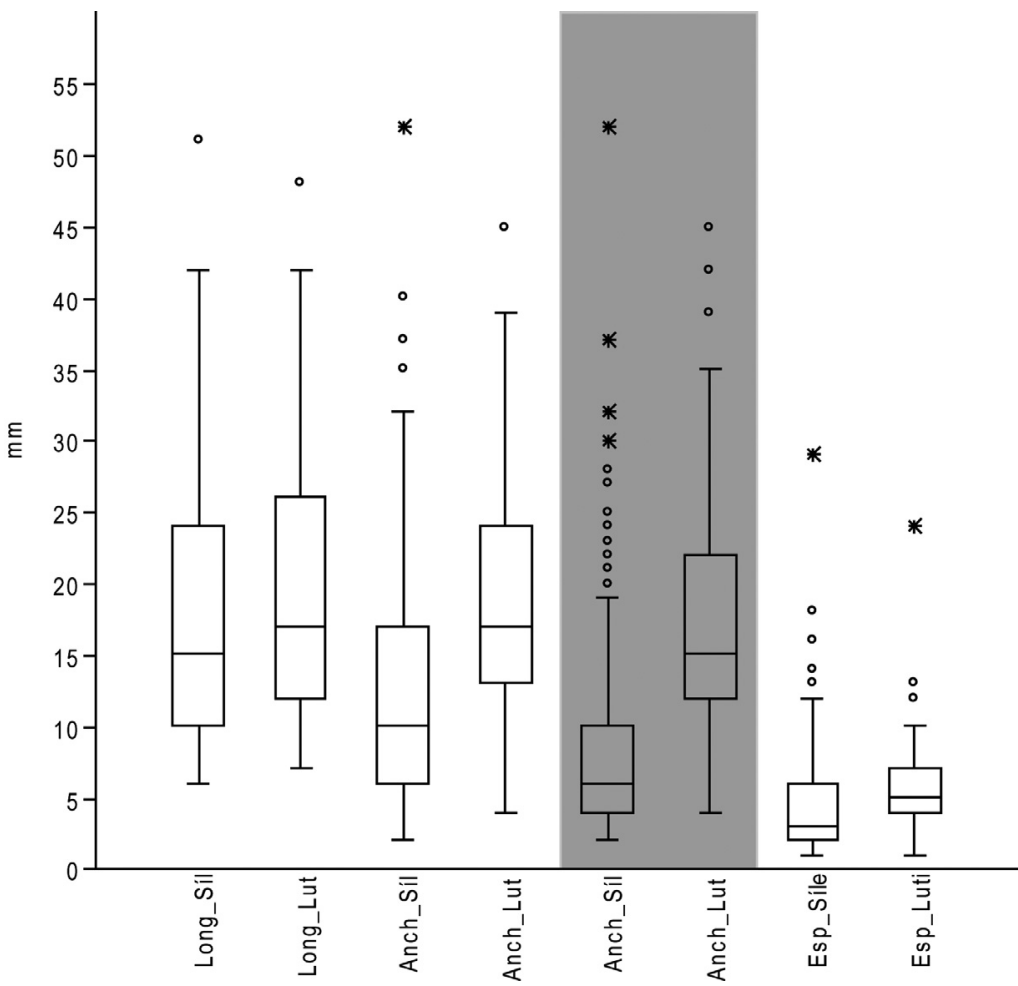

FIG. 10. Comparación tipométrica de los restos enteros de lutita y de sílex; sombreados en gris aparecen las anchuras de los restos enteros más los fragmentos proximales, distales y mesiales.

poco frecuentes pero también están presentes. La proporción entre el número de restos de sílex del Flysch y la de Treviño es de 3:1.

El conjunto de sílex está claramente dominado por los soportes laminares, mientras que la presencia de lascas es muy escasa. Los núcleos y restos de fabricación de soportes laminares son también escasos en relación a la abundancia de soportes de plena producción alcanzando un ratio de 1:60. Esto puede indicar que los soportes se introducen al yacimiento de manera masiva ya conformados, lo cual puede ser razonable en el caso de las laminillas retocadas o las láminas de mayor tamaño, o que los procesos de fabricación realizados in situ son cortos y puntuales, realizándose a partir de núcleos ya preparados que no se agotan ni abandonan en el yacimiento, sino que son exportados fuera de él.

Los escasos núcleos laminares recuperados muestran una enorme sencillez en la preparación y explotación. Se seleccionan soportes de pequeñas dimensiones, tanto lascas espesas como fragmentos de bloque, para fabricar las laminillas. El proceso de fabricación se inicia con una escasa o nula preparación que incluye la extracción de lascas en los flancos. La plataforma de percusión no se acondiciona, observándose una preparación muy somera de la cornisa mediante abrasión. La cara de lascado es, en todos los casos, corta y apenas se corrigen las convexidades. La explotación de las laminillas es semitornante y unipolar, extrayéndose laminillas de bordes paralelos, en ocasiones convergentes en el extremo distal.

El conjunto laminar es bastante heterogéneo, comprendiendo desde soportes de apenas $3 \mathrm{~mm}$ de anchura hasta soportes que superan los $20 \mathrm{~mm}$. El análisis del histograma de distribución de la anchura de los soportes laminares y la observación de la curvatura suavizada (Kernell) de dicha distribución, realizada mediante el programa informático PAST 2.04 (Hammer et al., 2001), nos ha permitido proponer una división de los soportes laminares en cuatro grandes grupos mediante Mixture Analysis (Brochier, 2008; Monchot et al., 2005; Chauvin, 2012). Se trata de un grupo de laminillas con valores comprendidos en torno a $4 \mathrm{~mm}$ de anchura, parte del cual se corresponde con la explotación realizada in situ; otro de laminillas anchas con valores en torno a $7 \mathrm{~mm}$; uno laminar con valores en torno a $10 \mathrm{~mm}$, y uno de láminas anchas, muy escaso, con valores en torno a $18 \mathrm{~mm}$ (Fig. 12).

Las características de los soportes laminares de menor tamaño son muy homogéneas, destacando las secciones trapezoidales, los perfiles rectilíneos $\mathrm{y}$, en los casos en los que se conservan, talones puntiformes, lisos y lineales. Estas características se corresponden con las de los núcleos recuperados en este nivel.

Otra categoría tecnológica abundante son los restos generados en la fabricación y reparación de útiles retocados. Son especialmente abundantes las 
lascas de reavivado bifacial, muchas de ellas de sílex de Treviño. Son también comunes los golpes de buril, que pueden estar relacionados tanto con la fabricación de buriles como con la preparación de caras de lascado de núcleos laminares sobre filo de lasca.

La producción de laminillas estrechas se destina fundamentalmente a la fabricación de laminillas de dorso. Las laminillas anchas se destinan también a fabricar dorsos de mayores dimensiones. Las láminas estrechas se utilizan en la fabricación de buriles, láminas retocadas y puntas de escotadura solutrenses. Por último, las láminas más anchas se importan bajo la forma de buriles, láminas truncadas y raspadores. Las lascas generadas en los procesos de fabricación laminar se utilizan para fabricar escotaduras, raederas, denticulados y especialmente raclettes.

Entre el utillaje retocado destacan las laminillas de dorso fabricadas fundamentalmente a partir de laminillas estrechas (Fig. 13). Estas se conforman con retoque abrupto, relativamente espeso, en ocasiones conformando bidorsos (Fig. 15, n. $\left.{ }^{\text {s }} 7-33\right)$. Un número
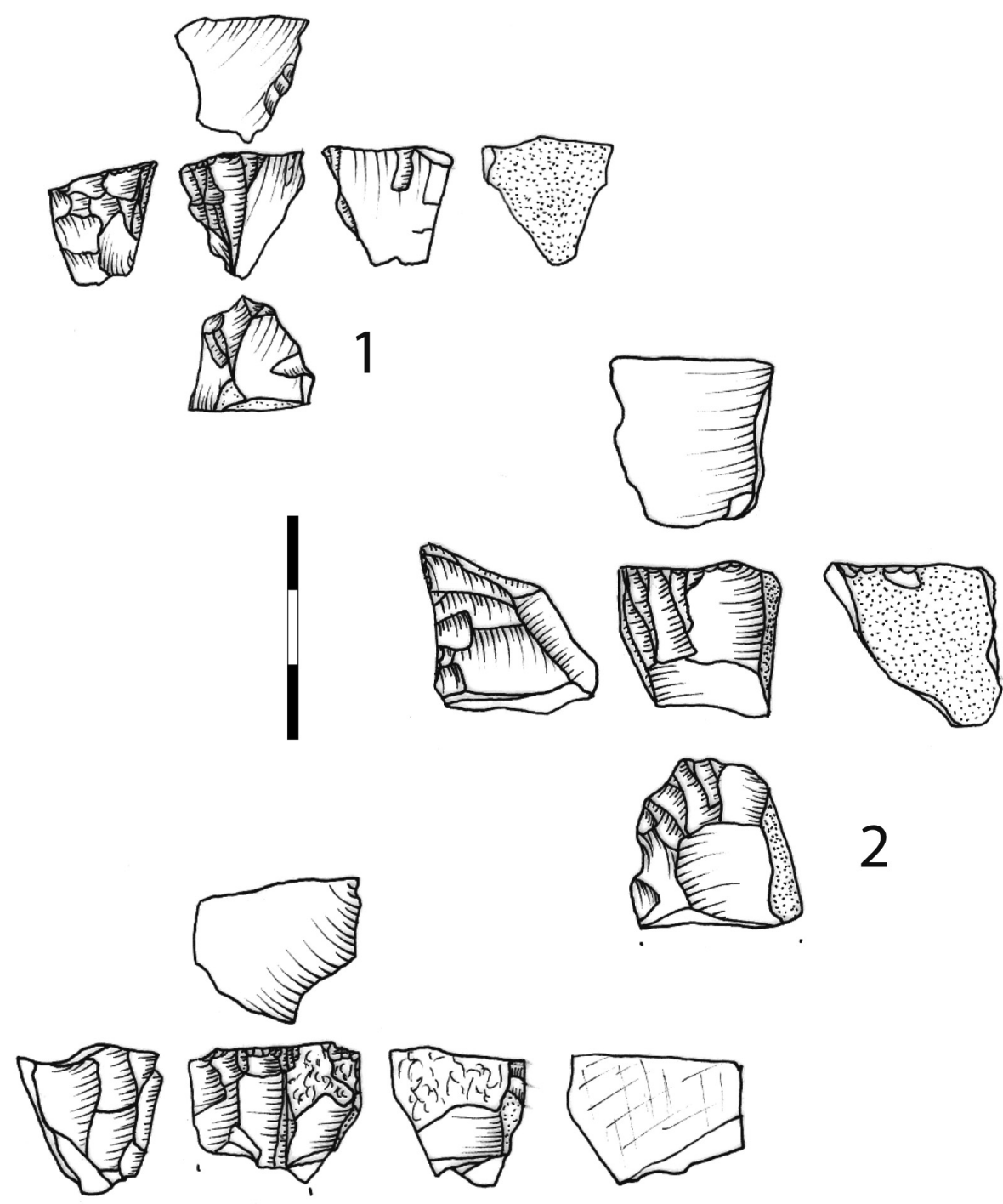
importante de estas lamini-
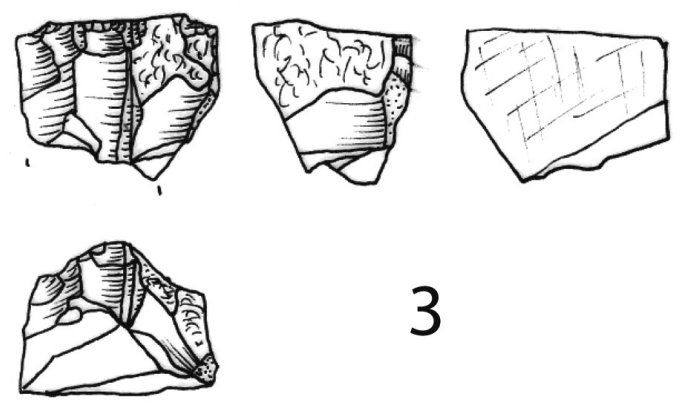

3

FIG. 11. Núcleos de laminillas de sílex del nivel II.

llas presenta fracturas derivadas de impactos provocados en un uso como armaduras de proyectil (Fig. 14, n. $\left.{ }^{\text {ss }} 1-3\right)$. El utillaje de sustrato - muescas, denticulados y raederas- es numeroso, así como las raclettes, las piezas astilladas y los perforadores (Fig. 16). Otras categorías de utillaje, como los buriles, los raspadores o las láminas retocadas, están menos representadas.
Hay que destacar, por último, las puntas con retoque plano. Estas están fabricadas a partir de láminas estrechas (Fig. 15, n. ${ }^{\text {os }} 1-4$ ) y presentan retoque plano bien bifacial y cubriente, bien unifacial. Todas están fragmentadas, algunas de ellas con claras fracturas de impacto (Fig. 14, n. ${ }^{\circ} 4$ ). Sólo una de ellas (Fig. 15, n. ${ }^{\circ} 4$ ), que conserva la parte 

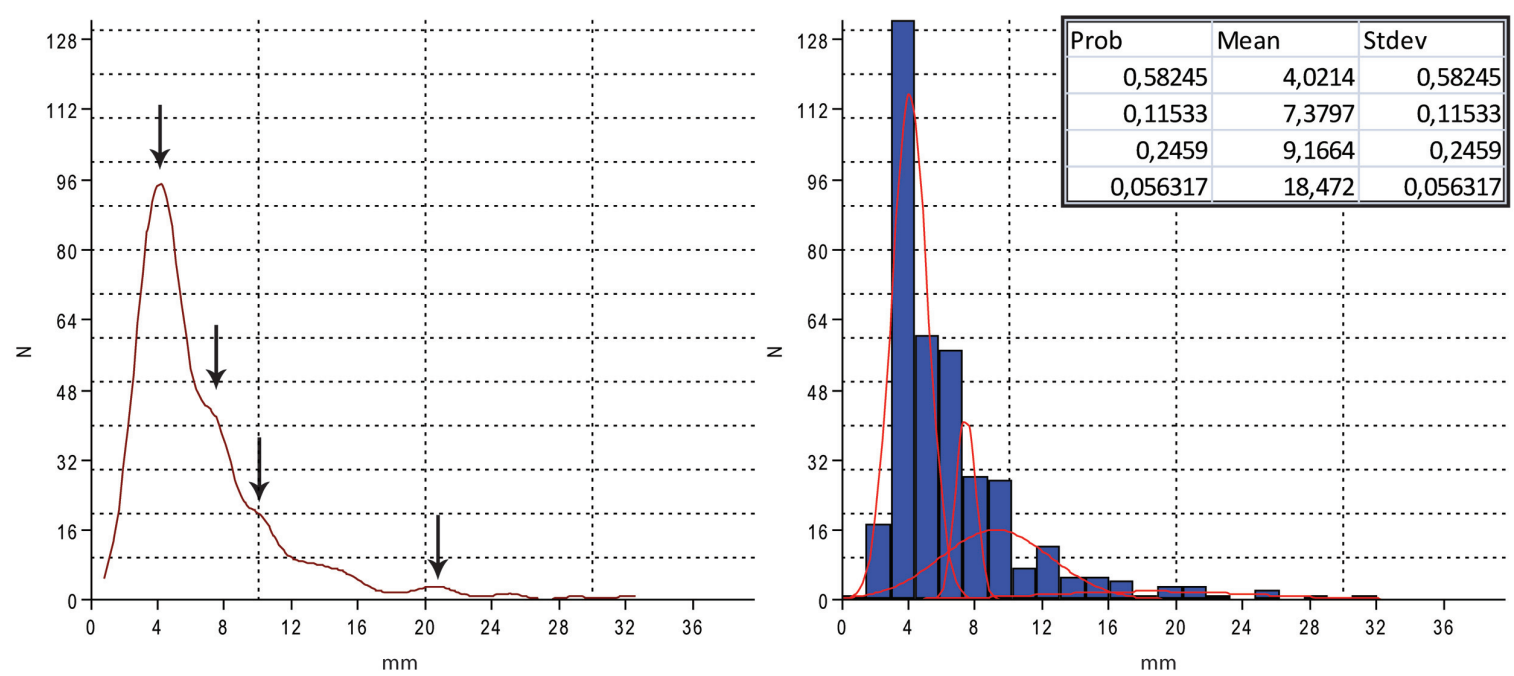

Fig. 12. Mixture Analysis de las anchuras de los soportes laminares: derecha, curva suavizada mediante el método Kernel con los picos identificados e izquierda, resultados del Mixture Analysis con la distribución de los cuatro grupos identificados.

\begin{tabular}{|c|c|c|c|c|c|c|c|}
\hline Clasificación tipológica & CR & $\mathrm{CZ}$ & LI & $\mathbf{L}$ & $S$ & Total & $\%$ \\
\hline 3. Raspador doble & & & & & 1 & 1 & 0,59 \\
\hline 5. Raspador sobre lámina retocada & & & & & 2 & 2 & 1,18 \\
\hline 8. Raspador sobre lasca & & & & 1 & & 1 & 0,59 \\
\hline 11. Raspador carenado & & & & & 1 & 1 & 0,59 \\
\hline 10. Raspador unguiforme & 1 & & & & & 1 & 0,59 \\
\hline 23. Perforador & & & & & 3 & 3 & 1,78 \\
\hline 24. "Bec" & & & & 1 & 4 & 5 & 2,96 \\
\hline 26. Microperforador & & & & & 1 & 1 & 0,59 \\
\hline 29. Buril diedro de ángulo & & & & & 1 & 1 & 0,59 \\
\hline 40. Buril múltiple sobre truncadura & & & & & 2 & 2 & 1,18 \\
\hline 43. Buril nucleiforme & & & & & 1 & 1 & 0,59 \\
\hline 44. Buril plano & & & & 1 & 1 & 2 & 1,18 \\
\hline 50. Microgravette & & & & & 2 & 2 & 1,18 \\
\hline 58. Lámina con borde abatido total & & & & & 1 & 1 & 0,59 \\
\hline 59. Lámina con borde abatido parcial & & & & & 1 & 1 & 0,59 \\
\hline 60. Lámina con truncadura retocada recta & & & & & 1 & 1 & 0,59 \\
\hline 62. Lámina con truncadura retocada cóncava & & & & & 2 & 2 & 1,18 \\
\hline 65. Lámina con retoque continuo sobre un borde & & & & & 4 & 4 & 2,37 \\
\hline 66. Lámina con retoque continuo en ambos bordes & & & & & 2 & 2 & 1,18 \\
\hline 70. Hoja de laurel & & & & & 1 & 1 & 0,59 \\
\hline 72. Punta con muesca típica solutrense & & & & & 1 & 1 & 0,59 \\
\hline 70-72. Fragmentos de puntas foliáceas & & & & & 3 & 3 & 1,78 \\
\hline 74. Escotadura & & & & 2 & 2 & 4 & 2,37 \\
\hline 75. Denticulado & & & 1 & 1 & 3 & 5 & 2,96 \\
\hline 76. Pieza astillada & & & & & 4 & 4 & 2,37 \\
\hline 77. Raedera & & 2 & & 1 & 6 & 9 & 5,33 \\
\hline 78. "Raclette" & & & & & 7 & 7 & 4,14 \\
\hline 84. Laminilla truncada & & & & & 1 & 1 & 0,59 \\
\hline 85. Laminilla con dorso & & & & & 63 & 63 & 37,28 \\
\hline 86. Laminilla con dorso truncada & & & & & 1 & 1 & 0,59 \\
\hline 88. Laminilla denticulada & & & & & 1 & 1 & 0,59 \\
\hline 89. Laminilla con escotadura & & & & & 1 & 1 & 0,59 \\
\hline 90. Laminilla Dufour & & & & & 5 & 5 & 2,96 \\
\hline 92. Diversos & & & & 5 & 24 & 29 & 17,16 \\
\hline Total general & 1 & 2 & 1 & 12 & 153 & 169 & \\
\hline
\end{tabular}

FIG. 13.

Clasificación tipológica del utillaje litico del nivel II, según la lista tipo de Sonneville-Bordes y Perrot (1954-56).

Abreviaturas CR: cristal de roca; CZ: cuarzo; L: lutita; LI: limonita; O: ocre $y$ s: silex. 


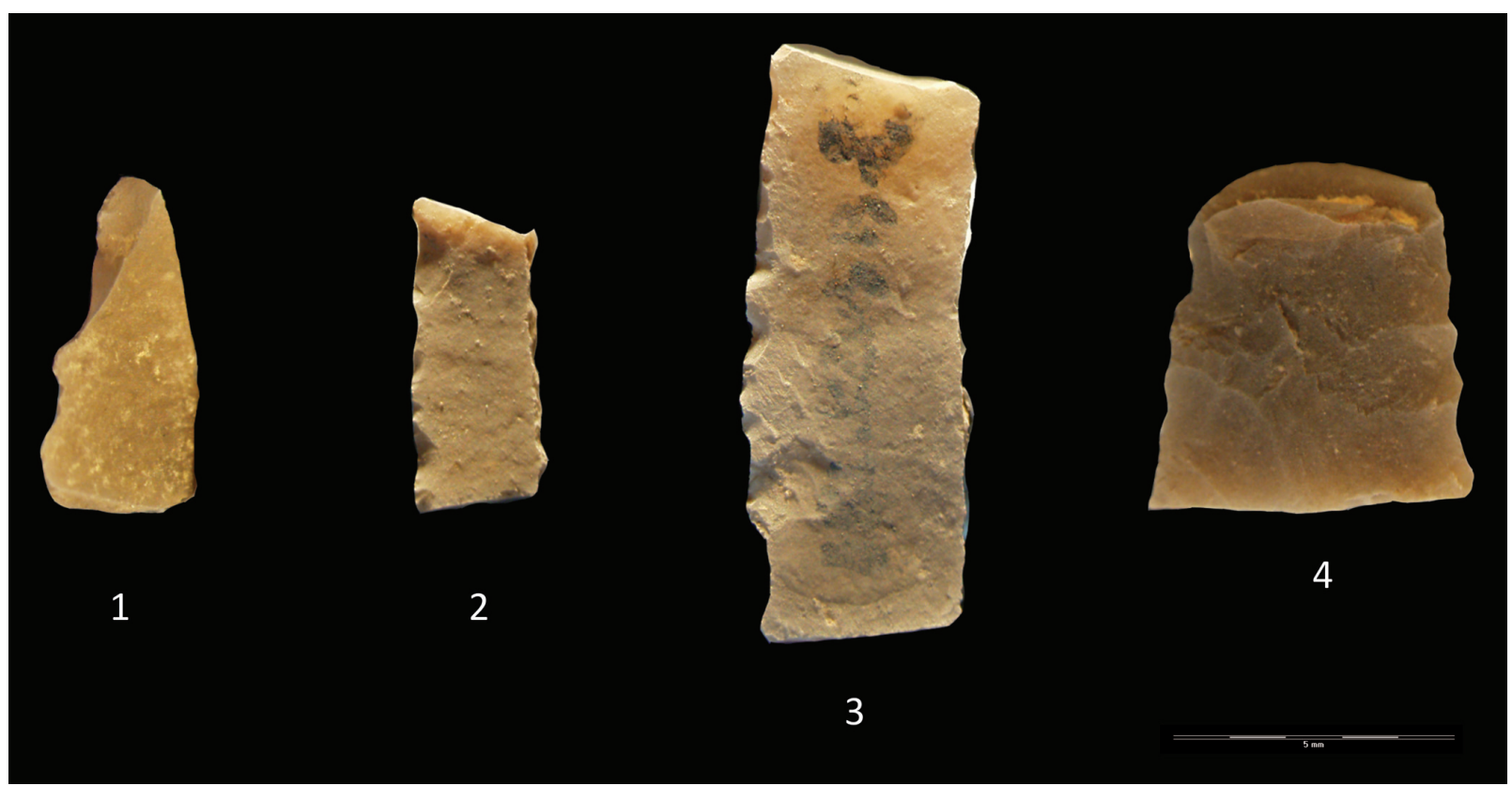

FIG. 14. Fracturas de impacto en laminillas de dorso: 1. burinante; 2-3. desconchados oblicuos y 4. fragmento de foliácea con fractura latente en lengüeta.

proximal, puede interpretarse como un fragmento de punta de muesca típica.

Por último, hay que señalar 13 útiles macrolíticos poco o nada configurados entre los que destacan cinco percutores - tres de lutita, uno de cuarcita y uno de arenisca-, uno de los cuales presenta depósitos de ocre relacionados bien con el uso, bien con un afán decorativo; cuatro plaquetas -dos de ocre y dos de arenisca-, una de las cuales presenta una intensa rubefacción en una superficie plana, lo que plantea un uso como lámpara o superficie refractaria para el procesado de alimentos; tres retocadores - dos de lutita y uno de limonita-, y un fragmento de canto de arenisca con huellas de abrasión por uso.

El conjunto de la industria lítica del nivel II muestra un carácter mixto y sugiere que el rango de actividades realizado durante las ocupaciones de Arlanpe fue amplio. Combina la reparación/sustitución de útiles relacionados con la caza como las armaduras microlíticas o las puntas foliáceas con un utillaje variado y doméstico, que se fabrica in situ, como en el caso del utillaje de lutita o del utillaje macrolítico, o que se importa ya configurado, como en el caso de los raspadores, buriles, raclettes o piezas astilladas de sílex.

\subsection{Industria ósea}

El utillaje óseo recuperado en el nivel II se caracteriza por su escasez y su diversidad tanto tipológica como funcional, encontrándose tanto útiles relacionados con la vida cotidiana - una aguja, una espátula-, como otros asociados a la caza -dos azagayas-.

La espátula presenta una forma alargada y sección aplanada por estar realizada en un fragmento de costilla perteneciente a un animal de talla media -dimensiones máximas de $27 \times 8 \times 3 \mathrm{~mm}-$. Uno de sus extremos longitudinales se encuentra muy redondeado debido al desgaste funcional del útil mediante la fricción con la materia trabajada.

La única aguja encontrada hasta el momento se encuentra realizada en hueso y presenta unas dimensiones máximas de 61 × 54 × $3 \mathrm{~mm}$. Su recuperación fue compleja ya que apareció fracturada en 6 partes. Aún así, se conserva casi completa, faltándole una pequeña fracción de sus dos extremos. El extremo proximal presenta una fractura por presión achacable al uso o a la reconfiguración del ojal (Corchón y Garrido, 2007a, 2007b), en cambio la fractura de su área distal es postdeposicional (Fig. 17, n. ${ }^{\circ}$ 2). A pesar de que la aguja propiamente dicha no presenta huellas tecnológicas de 


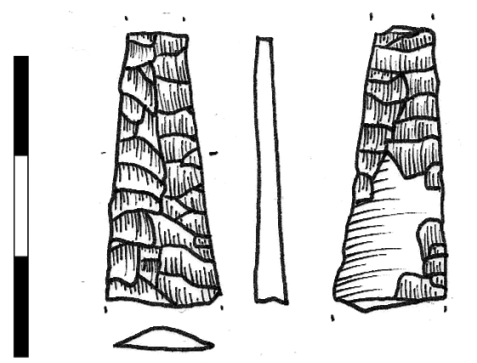

1

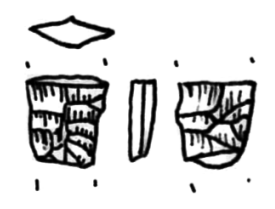

2

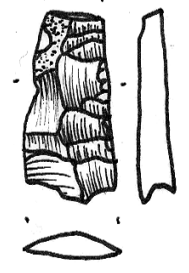

3

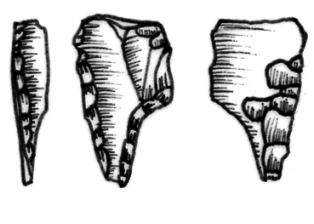

4

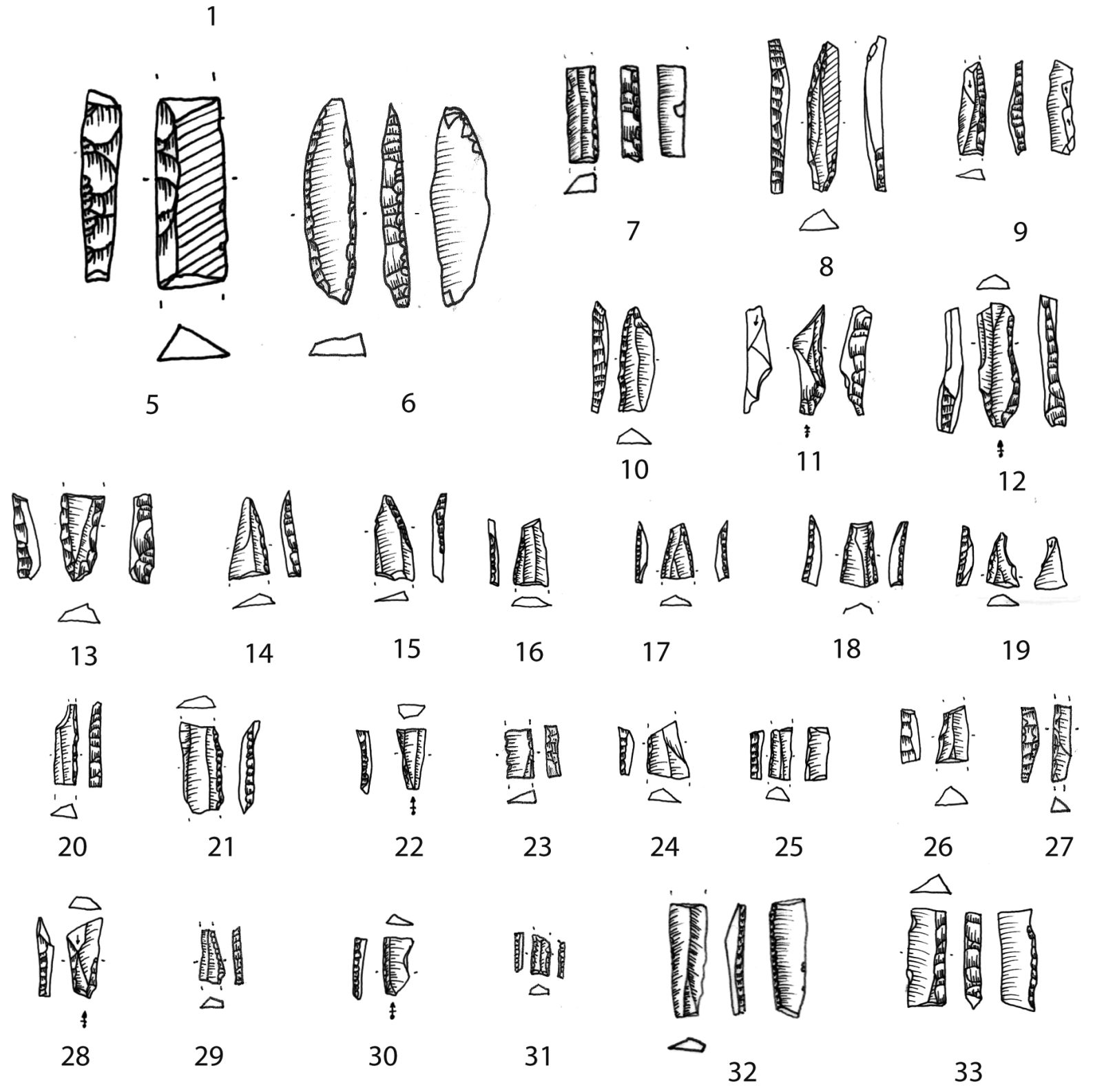

FIG. 15. Armaduras de proyectil del nivel II: 1-4. fragmentos de puntas foliáceas típicas solutrenses; 5-6. Microgravettes y 7-33. laminillas de dorso. 

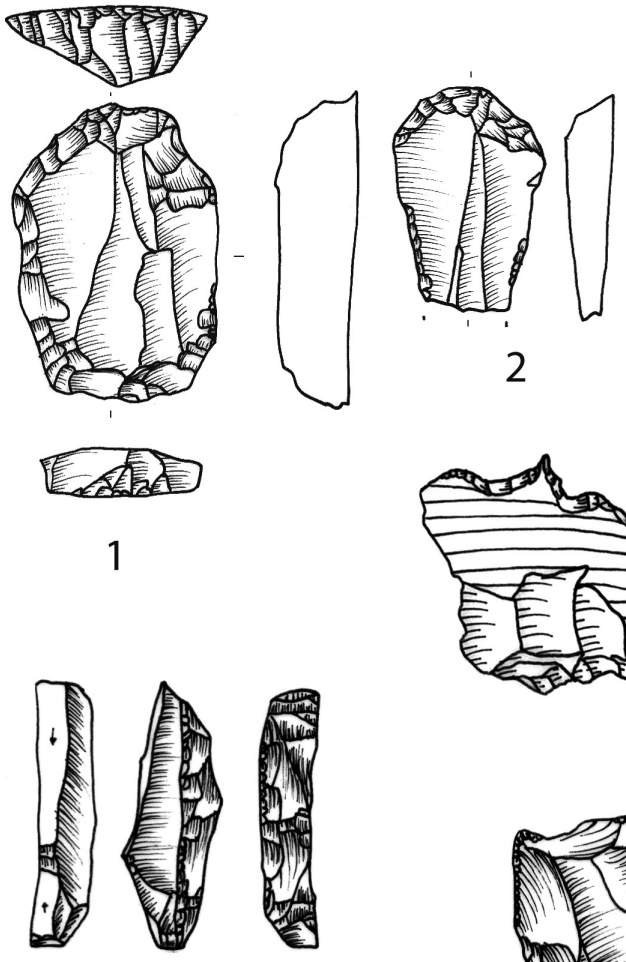

5
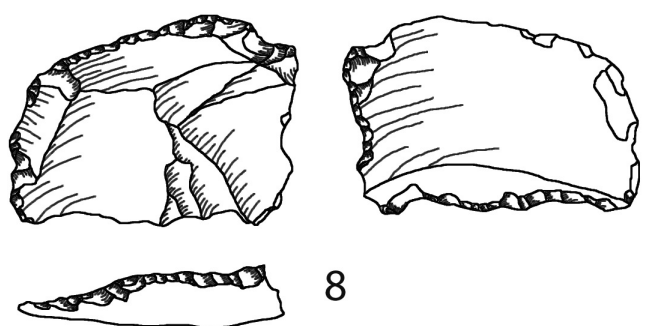

8
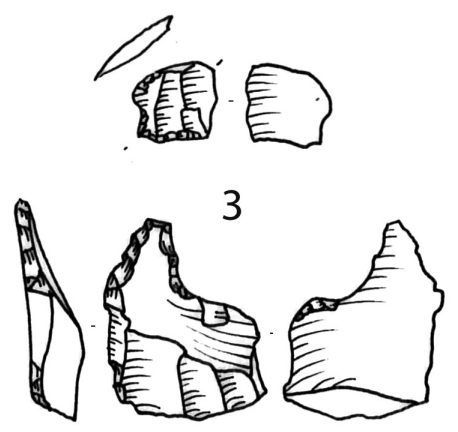

4
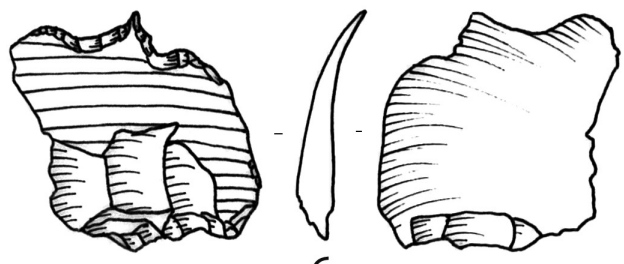

6
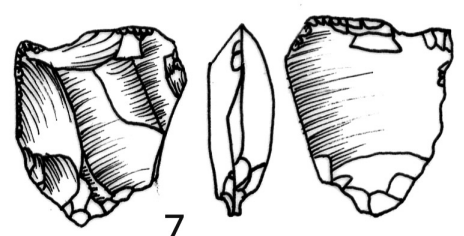

7
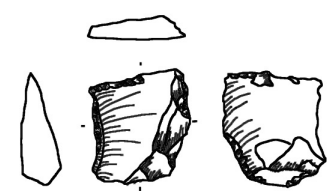

9

FIG. 16. Útiles retocados de sillex: 1-2. raspadores; 3-4 y 6. perforadores; 5. buril sobre truncadura; 7. pieza astillada; 8 y 9. raclettes.

extracción, esta actividad ha sido constatada en un fragmento de diáfisis fracturado en estado fresco tras ser ranurado o aserrado longitudinalmente recuperado en el mismo nivel. La superficie cortical de este hueso conserva dos surcos paralelos -3 $\mathrm{mm}$ de distancia- que convergen en el extremo, realizados según el eje morfológico del hueso. Este tipo de ranurado convergente suele tener como objetivo, según las observaciones experimentales realizadas (Corchón y Garrido, 2007b), la obtención de un soporte alargado y apuntado. El reducido espesor del hueso sugiere que probablemente el objetivo, no completado, era obtener un soporte para realizar una aguja (Fig. 17, n. $\left.{ }^{\circ} 3\right)$.

De las dos azagayas recuperadas destaca una de base recortada, planta triangular y sección cuadrangular, abandonada en proceso de fabricación. Esta azagaya nunca llegó a ser utilizada y aún conserva las "marcas de ranurado" (Garrido, 2008) en sendos laterales del útil. Unas profundas incisiones oblicuas y superpuestas a estas últimas revelan que la varilla fue extraída mediante la introducción de una cuña de sílex en la ranura y un posterior movimiento de palanca realizado en varios puntos de la varilla hasta obtener finalmente su extracción. El soporte fue parcialmente configurado en su parte distal mediante raspado antes de ser fracturado por su actual área basal. El resto de la superficie dorsal está sin transformar y conserva el aspecto natural del tejido cortical del asta. La cara dorsal, en cambio, ha sido someramente rebajada, eliminándose parte del tejido esponjoso interno del asta. La forma escalonada de la sección de la zona basal parece indicar que la fractura pudo haberse realizado mediante la incisión de ranuras transversales en ambas caras y sendos laterales. Como el escalonamiento de una u otra cara no coinciden ni llegan a contactar entre sí, probablemente la fractura se culminó mediante la flexión del fuste (Fig. 17, n. ${ }^{\circ}$ ). 


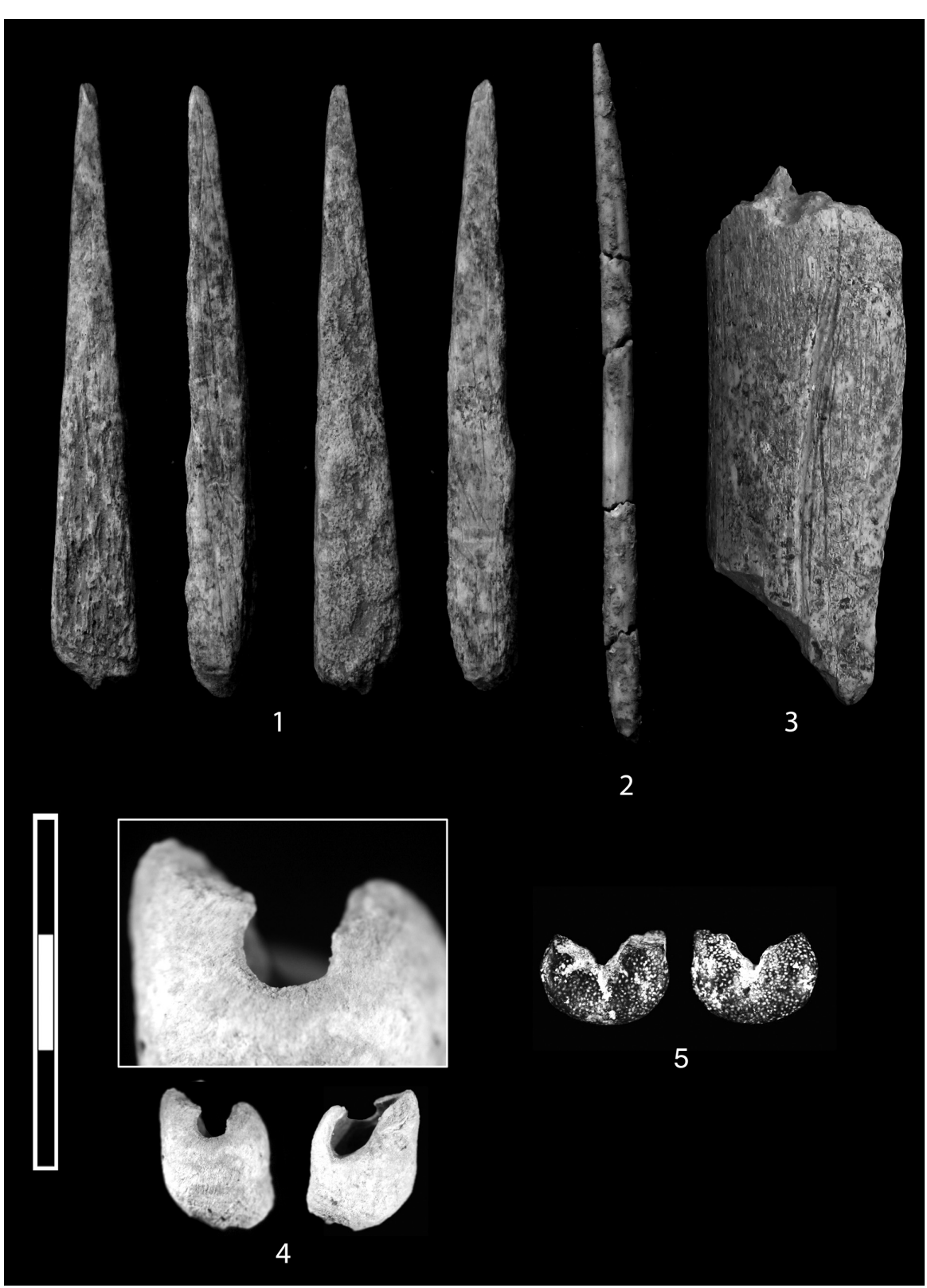

FIG. 17. Otros útiles: 1. azagaya de sección cuadrangular; 2. aguja; 3. hueso ranurado; 4. colgante sobre Nucella lapilus y 5. colgante sobre canto de limonita.

Por último, se han recuperado tres fragmentos de hueso de reducido tamaño con incisiones oblicuas y paralelas que pueden estar relacionados con algún tipo de actividad gráfica intencional.

\subsection{Objetos de adorno}

Los objetos de adorno recuperados en el nivel II de Arlanpe están realizados sobre concha y mineral. La concha perforada de Nucella lapilus (I. Gutiérrez Zugasti, com. pers.) presenta una forma lobular con el ápice fracturado o desgastado (12 x $8 \times 7 \mathrm{~mm}$ ). La perforación, en un único sentido, se localiza en el labro junto al canal sifonal. Se trata de un orificio de 2 $\mathrm{mm}$ de diámetro, realizado desde el exterior de la concha, que se encuentra abierto por la rotura en el borde parietal del peristoma. La diferencia de pátina entre la perforación y la rotura indicaría que esta no se produjo durante el proceso de fabricación del colgante sino en un momento posterior (Fig. 17, n. ${ }^{\circ}$ ).

El otro colgante es un fragmento de un pequeño

La segunda de las azagayas recuperadas es un fragmento mesial en asta de ciervo, de sección oval. Las dimensiones máximas de la pieza son 27 x 5 x $3 \mathrm{~mm}$ y se encuentra fracturada por ambos extremos longitudinales. La alteración de las superficies por procesos postdeposicionales ha impedido encontrar huellas macroscópicas de configuración. canto de limonita de forma discoidea y sección plana $(10 \times 7 \times 3)$. En la zona central se observa parte de un orificio de perforación que ha sido atacado por ambas caras. La parte conservada del orificio tiene un diámetro de 1,5 mm (Fig. 17, n. ${ }^{\circ}$ ). 


\subsection{Fauna}

La fauna del nivel II recuperada en las campañas de 2006-2009 se caracteriza por un elevadísimo índice de fracturación. El número total de restos recuperados es de 16417, de los cuales sólo se han identificado 296. Los restos no identificados muestran una historia tafonómica compleja, con marcadas alteraciones antrópicas -fracturas, huellas de corte, cremación- y naturales -fracturas diagenéticas, carnívoros, microorganismos, precipitación de manganeso, raíces, etc.-.

El conjunto de restos identificados está dominado por herbívoros (Fig. 18). Las dos especies más importantes son la cabra montés - Capra pyrenaica- y el rebeco-Rupicapra pyrenaica-, algo que se repite en otros niveles del yacimiento $^{2}$. De estas dos especies los restos dentales y huesos de las extremidades -falanges y carpotarso- son los más representados. Se han podido identificar cuatro individuos diferentes - una cabra y tres rebecos- en base a la dentición.

El resto de las especies de herbívoros están peor representadas y son, por este orden, el ciervo -Cervus elaphus- y el gran bóvido. Los restos de carnívoros son de zorro -Vulpes vulpes-, oso -Ursus sp.- y de un félido de gran tamaño -Panthera sp.-.

Este patrón de representación, en el que los animales de roquedo dominan sobre otros, coincide con el de algunos yacimientos cantábricos situados en zonas abruptas como Amalda, Mirón o Bolinkoba (Yravedra, 2002). El pequeño número de elementos que se han podido determinar taxonómicamente no nos permite abordar con seguridad cuestiones como la representación esquelética, que nos ayudaría a conocer si las carcasas fueron introducidas completas o no.

\section{Caracterización de las ocupaciones del final del Solutrense de Arlanpe (nivel II)}

A pesar de la escasa superficie excavada, las reducidas dimensiones de la cueva de Arlanpe y la

${ }^{2}$ Gómez-Olivencia, A.; Arceredillo-Alonso, D.; RiosGaraizar, J.; Garate, D.; Iriarte, E. y San Pedro, Z.: "Dental Anomalies in the Mandible of Capra pyrenaica: Presence of Two Permanent Fourth Premolars in a Pleistocene Wild Goat from Arlanpe Cave (Bizkaia, Northern Spain)", International Journal of Osteoarchaeology, en prensa.

\begin{tabular}{|lr|}
\hline \multicolumn{1}{|c|}{ Taxón } & $\begin{array}{c}\text { NR del } \\
\text { nivel II }\end{array}$ \\
\hline Artiodactyla indet. & 180 \\
\hline Bovidae indet. & 1 \\
\hline Gran bóvido (Bos primigenius/Bison priscus) & 1 \\
\hline Caprinae indet. & 14 \\
\hline Capra pyrenaica & 33 \\
\hline Rupicapra pyrenaica & 20 \\
\hline Cervidae indet. & 9 \\
\hline Cervus elaphus & 5 \\
\hline Total herbívoros & 263 \\
\hline Carnivora indet. & 12 \\
\hline Vulpes vulpes & 3 \\
\hline Ursus sp. & 7 \\
\hline Panthera sp. & 1 \\
\hline Total carnívoros & 23 \\
\hline Aves & 10 \\
\hline TOTAL & 296 \\
\hline
\end{tabular}

FIG. 18. Número de restos (NR) para cada taxón del nivel II ("Entrada") de los años 2006 a 2010.

constatación de que estas ocupaciones no debieron extenderse más allá de la zona media de la cueva, el registro obtenido es significativo y característico de las ocupaciones humanas producidas durante el Solutrense. El análisis de la industria lítica, de la industria ósea, de los objetos de adorno y de la fauna del nivel II nos ha permitido describir las siguientes características:

a) Combinación en el uso de sílex, importado, y de lutita local. Ambas materias primas están sometidas a distintos procesos productivos, y se destinan a usos diferenciados.

b) El sílex se importa bajo la forma de útiles retocados - puntas foliáceas, buriles, raspadores-, núcleos de laminillas y láminas brutas. La producción realizada in situ se destina a fabricar laminillas de dorso para conformar y reparar armas de proyectil compuestas. Otras actividades realizadas con el sílex implican el uso de piezas astilladas, el raspado, el ranurado, las perforaciones, etc.

c) La lutita se gestiona de manera menos planificada. Se fabrican in situ útiles de mayor tamaño, 
en ocasiones macrolíticos, que se usan sin modificación por retoque, en tareas pesadas.

d) Se ha documentado la fabricación de puntas óseas. Además hay otros útiles de hueso -aguja, espátula- destinados a actividades domésticas.

e) La producción de objetos de adorno no es importante en Arlanpe, ya que sólo se abandonan y quizás ocasionalmente se fabrican algunos de ellos.

f) A pesar de carecer de datos tafonómicos concluyentes, en parte debido al intenso grado de fracturación de los restos de fauna, parece que no se produce un aporte completo de los animales.

g) Hay evidencias de uso del fuego, pero se trata en todos los casos de pequeños hogares poco o nada estructurados.

Las características descritas permiten proponer una interpretación funcional de las ocupaciones del nivel II de Arlanpe como un hábitat ocasional que aúna actividades propias de un alto de caza, como la preparación de armamento o el oteo de manadas animales, con otras más propias de hábitats o espacios domésticos como el uso del fuego, el procesado de alimentos, las actividades de fabricación de objetos en los que intervienen útiles como agujas, raspadores, buriles y perforadores, o la realización de tareas pesadas, probablemente de procesado primario, en las que se usa el utillaje de lutita.

Además, la lectura de la proveniencia de las materias primas, la forma en la que estas se importan y las propias características del nivel II indican que el yacimiento funcionó como un lugar de habitación efímero, ocupado de manera repetida por poblaciones que tenían territorios de influencia amplios, gestionados de manera compleja. En un artículo reciente Straus y González Morales (2009) plantean un modelo de gestión territorial para el Cantábrico en el que habría yacimientos situados cerca de la costa como La Riera o Antolińako Koba, que funcionarían como campamentos residenciales, y una serie de yacimientos de montańa situados al interior, como
Mirón, que funcionarían como cazaderos dedicados a explotar ese tipo de paisajes. Los datos acerca de la procedencia de las materias primas de Arlanpe así como los de otros yacimientos como Antoliñako Koba (Tarriño, 2006) y de Bolinkoba (obs. personal) indican que, al menos para el ámbito del Cantábrico oriental, este modelo de movilidad costa-montaña no explica la complejidad y la amplitud del territorio explotado que incluiría también los territorios de la Llanada Alavesa. Dentro de este modelo de desplazamiento los sitios de interior como Arlanpe o Bolinkoba funcionarían más como campamentos intermedios, combinando actividades cinegéticas con cierta actividad doméstica, que como cazaderos en el sentido más estricto del término, lo que sugiere una movilidad más residencial que logística.

\section{El nivel III}

El nivel III es el resultado del colapso de las madrigueras excavadas en el nivel IV y está compuesto fundamentalmente por materiales del nivel II. Esto nos obliga a evaluar con muchas reservas este conjunto a pesar de que sus características industriales y su composición faunística no son muy diferentes de las descritas para el nivel II.

El conjunto lítico de este nivel está compuesto por 563 restos líticos, de los cuales más del 60\% son esquirlas y fragmentos informes. La proporción de sílex alcanza únicamente el 63\% mientras que la lutita se sitúa en el 25\%. La composición tecnológica destaca por una alta proporción de laminillas y un escaso número de núcleos y productos de acondicionamiento laminar. Las lascas de reavivado, especialmente las bifaciales, son abundantes. Los útiles retocados apenas alcanzan los 46 efectivos. Destacan las laminillas de dorso, los microperforadores, un fragmento de hoja de laurel y un microlito geométrico - un segmento de círculo- semejantes a los recuperados en el nivel IV de Amalda (Baldeón, 1990) y en el solutrense de Aitzbitarte y Ermittia (Straus, 1974). Entre la lutita destacan las lascas corticales y simples, siendo escasos los útiles retocados.

El único resto de industria ósea recuperado en el nivel III es un fragmento mesial de aguja de 
hueso, de la que se conserva el vástago y el arranque del ojal realizado a partir de un rebaje previo del volumen cilíndrico del vástago. Entre los objetos de adorno cabe destacar un colgante realizado sobre un canino de ciervo.

La fauna del nivel III está compuesta básicamente por herbívoros -NR = 185-. Entre los taxones que se han podido clasificar a nivel específico destaca la gran abundancia de Capra pyrenaica $-\mathrm{NR}=103-$, de los que algo más de la mitad corresponden a un esqueleto parcial de cabra montés recuperado en la excavación del año 2006 (Rios et al., 2008). Otros herbívoros representados son el sarrio -Rupicapra pyrenaica; $\mathrm{NR}=13-$, el ciervo $-\mathrm{NR}=5-$, el corzo $-\mathrm{NR}=1-\mathrm{y}$ el reno-Rangijer tarandus- $\mathrm{NR}=1$. Las aves $-\mathrm{NR}=11-\mathrm{y}$ los carnívoros $-\mathrm{NR}=19-$ también están representados. Entre estos últimos sólo se ha podido reconocer a nivel específico la presencia de zorro - Vulpes vulpes; NR= $4-\mathrm{y}$ oso - Ursus sp.; $\mathrm{NR}=4-$.

\section{Arlanpe y el final del Solutrense cantábrico}

El registro arqueológico del Solutrense en general, y especialmente del final de este periodo, adolece de una serie de problemas derivados de la escasez de secuencias bien datadas y publicadas en detalle. Estas carencias condicionan el análisis de conjunto e impiden avanzar en la demostración de las distintas hipótesis acerca del final del Solutrense. La presentación de los resultados obtenidos en Arlanpe permite contrastar algunas de las cuestiones generales planteadas para el final del Solutrense.

Uno de los principales debates se articula en torno a la definición de los conjuntos cantábricos fechados entre 18000 y 16500 uncal. BP aproximadamente. En estos conjuntos, entre los que se encontraría Arlanpe, se han venido identificando unas características comunes que podrían resumirse en la "rarificación del utillaje característico solutrense, notable disminución del tamaño del utillaje, creciente importancia de la cuarcita, mayor significación de las laminillas de dorso y cierta simplificación en la morfología y tecnología del utillaje" (De La Rasilla, 1996: 104), y tradicionalmente se definían como Solutrense superior final, Solutrense terminal o Solutrense en proceso de desolutreanización, aunque había autores que proponían una atribución al Badegouliense (Bosselin y Djindjian, 1999; cf. Straus y Clark, 2000). En una reciente publicación (Aura et al., 2012) se reaviva este debate proponiéndose la atribución de todos los niveles con dataciones posteriores al 18000 uncal. BP al Magdaleniense arcaico. Se argumenta para ello la posible mezcla de materiales solutrenses y magdalenienses por distintos procesos geológicos o tafonómicos, lo que podría explicar algunas de las características del Solutrense superior final como la escasez relativa de puntas típicas solutrenses. Al mismo tiempo, se utilizan los mismos argumentos que antes servían para una atribución al final de Solutrense como base para una atribución al Magdaleniense arcaico, "The contexts which make up this phase are characterized by local raw material use, the production of flakes, an increase in backed bladelets, tools of archaic appearance and a few raclettes, and the virtual absence $(<3 \%)$ of Solutrean tool types" (Aura et al., 2012: 6; nótese la semejanza con la cita anterior de De La Rasilla, 1996). A estos argumentos se une en la industria ósea la presencia de "bone points of rounded or flat section and long basal bevel, and the use of the pseudo-excise decoration technique" (Aura et al., 2012: 6).

Esta línea argumental nos genera ciertos problemas. Coincidimos con los autores del citado trabajo en que puede haber dudas acerca de la integridad de algunos de los niveles implicados en esta problemática. No obstante, no nos parece razonable extrapolar las observaciones realizadas en unos yacimientos concretos a todos los contextos cantábricos, ni creemos que esta pueda ser la causa del carácter particular de los conjuntos datados entre 18-17000 uncal. BP. En el caso de Arlanpe no se han detectado problemas tafonómicos, más allá de las bioturbaciones que han sido correctamente aisladas, que pudiesen explicar la presencia de los elementos solutrenses asociados a una fecha de $c .17100$ uncal. BP. Es más, la abundancia en el mismo de lasquitas de retoque bifacial por presión apunta a que los útiles solutrenses no son elementos intrusivos. Además las dataciones obtenidas en el nivel II y la del nivel III son muy coherentes entre sí y sitúan claramente el 
conjunto de Arlanpe dentro de la cronología propuesta por Aura et al., para el Magdaleniense Arcaico cantábrico (95\%, 22240-19540 cal BP; Aura et al., 2012), sin que se hayan identificado en la secuencia estratigráfica de este yacimiento, en ninguno de los sectores excavados, niveles solutrenses de cronología más antigua.

Vemos también que los criterios referidos a la industria ósea son difíciles de contrastar en el registro arqueológico. La decoración pseudoexcisa, aparentemente elemento característico del Badegouliense, ha sido detectada únicamente en unos pocos conjuntos. La varilla de Aitzbitarte IV, localizada con unos materiales situados entre los niveles III y IV (Utrilla, 1986) es asociada por Aura et al. (2012) a la fecha de $17950 \pm 150$ uncal. BP. Sin embargo, esta fecha se obtuvo, según Altuna (1972: 155), de una muestra que "fue tomada de la base del nivel Solutrense: cuadro $14 \mathrm{~N}$ a la profundidad de $160 \mathrm{~cm}$ ", y data, por tanto, el rico conjunto solutrense del nivel IV. Los otros ejemplares, los del nivel III de Llonín, los de Cueva Rosa o Cueto de la Mina, provienen de niveles no datados. Además en la descripción que se hace de la industria del primero no se cita la presencia de útiles foliáceos, y en el caso de los dos últimos casos se trata de excavaciones antiguas. No hay por tanto razones para atrasar la presencia de este tipo de decoración en el Cantábrico más allá del 17000 uncal. BP o para asociarla a lo que se ha denominado Solutrense superior final.

Respecto a los argumentos referidos a la industria lítica carecemos aún de estudios tecnológicos suficientes para contrastar que las características definidas para el Magdaleniense arcaico o el Solutrense superior final sean comunes a todo el ámbito cantábrico. Por ejemplo, el modelo de aprovisionamiento de materia prima que hemos definido en Arlanpe es único en todo el Paleolítico superior del Cantábrico oriental y responde a la función particular del yacimiento. En esta parte del Cantábrico en ningún otro nivel solutrense se documenta un uso tan amplio de materias primas locales, tampoco en aquellos, como Amalda o Ermittia (Baldeón, 1990; Esparza y Mujika, 1999), que parecen corresponderse con una fase final de este periodo y tampoco en los del Magdaleniense inicial de Erralla o Ekain (Baldeón, 1985; Cazals y Langlais, 2005-2006). Hay algún ejemplo del uso materias primas distintas al sílex en el área centro-occidental cantábrica, como en el nivel 120-121 -Solutrense superior- del Mirón, con porcentajes que varían entre el 7 y el 19\%; el nivel 313 -Magdaleniense inicial/Solutrense superior final-, con un 12\%, o los niveles 117-119 del Mirón -Magdaleniense inicial-, con porcentajes similares (Straus et al., 2008, 2011). Este uso podría explicarse por razones funcionales concretas, sobre todo porque parece destinado, al igual que en Arlanpe, a la fabricación de utillajes masivos (ibidem). La situación parece diferente en el Cantábrico central y occidental, siendo variable el uso de materias primas distintas al sílex, con ejemplos como el del El Pendo o El Ruso I, con menos del 10\% (Muñoz, 2001; Muñoz y Serna, 1999). En Asturias el uso de la cuarcita es generalizado durante el Paleolítico superior (Fortea et al., 2010), y durante el Solutrense superior, y no sólo en sus fases finales (De la Rasilla y Santamaría, 2005-2006; Straus y Clark, 1986). Todo esto nos previene de considerar el aumento en el uso de las materias primas locales como una característica exclusiva del Solutrense superior final o del Magdaleniense arcaico y permite apuntar a otras causas estructurales, como la escasez de materia prima de calidad en el entorno -caso del cantábrico occidental-, o coyunturales, como la necesidad concreta de un utillaje masivo (Arlanpe n. II o Mirón n. 117-119), para explicar este uso de materias primas distintas al sílex.

Otro de los elementos que caracterizarían el final del Solutrense Cantábrico es la abundancia de laminillas de dorso frente a los elementos foliáceos, que se vuelven progresivamente más escasos. Esta transformación en el tipo de armamento utilizado puede estar relacionada con múltiples causas como la variación en el tipo preferido de presas, de las estrategias de caza o con un abandono de los procesos de producción de armamento lítico más costosos.

En Arlanpe la proporción de laminillas de dorso es extraordinariamente alta incluso teniendo en consideración que la recogida de restos pequeños ha sido muy rigurosa. Esto puede estar motivado por esos cambios generales o bien por los condicionantes litológicos y la función del sitio. De nuevo la ausencia de sílex en el entorno de la 
cueva tuvo que ser una de las causas que motivaron el traslado de sílex, en formatos manejables, desde la costa y desde Treviño. En este contexto el uso de laminillas facilita el transporte y favorece el ahorro de materia prima, por lo que es una solución óptima para aprovisionar a grupos de gran movilidad, más aún si esta estrategia se combina con otra que use las materias locales para las tareas más pesadas. Además en Arlanpe las laminillas de formato más pequeño parecen casi exclusivamente destinadas a configurar puntas multicompuestas, lo cual estaría relacionado con tareas de reparación del armamento de caza.

Esta situación parece generalizarse a partir del Solutrense superior. En los niveles de sitios como Aitzbitarte IV, Bolinkoba o Ermittia el porcentaje de laminillas de dorso no alcanza el 20\% del utillaje retocado (Straus, 1974; Esparza y Mujika, 1999), pero es probable que este dato esté condicionado por la metodología de cribado ${ }^{3}$. Sin embargo, en sitios excavados más recientemente como Amalda, El Pendo, La Riera o Morín (González Echegaray y Freeman, 1978; Straus y Clark, 1986; Baldeón, 1990; Muñoz, 2001), incluyendo en algunos de ellos el cribado por agua, los porcentajes de laminillas de dorso superan el 20\%, alcanzando en algunos casos como en Amalda o El Pendo porcentajes similares a los de Arlanpe. Hay, sin embargo, otros conjuntos como Las Caldas, El Ruso I, Chufín o Mirón en los que, pese a ser excavaciones recientes, estos utillajes alcanzan proporciones muy discretas (Cabrera, 1977; Corchón, 1990; Muñoz y Serna, 1999; Straus et al., 2011).

Esta relativa generalización del microutillaje de dorso viene acompañada de una rarificación del utillaje de retoque plano típico solutrense, lo que para algunos autores supone prácticamente la única diferencia entre el Solutrense y el Magdaleniense inicial (Straus et al., 2011). La transformación no sólo se aprecia en el descenso del número de puntas de retoque plano, sino en la propia configuración de las mismas. En el caso de Arlanpe es

${ }^{3}$ Ver por ejemplo los resultados tan dispares en el número de laminillas obtenidos por Mortureux y Sonneville-Bordes en las excavaciones antiguas de Caminade y los obtenidos por Bordes en las excavaciones recientes (Bordes, 2006). significativo que ninguna de las puntas de escotadura recuperadas en el nivel il presenta retoque bifacial completo (Fig. 16, n. ${ }^{\text {os }} 1-2$ ) y en algunos casos el retoque plano es muy parcial y limitándose al pedúnculo o a parte de la cara dorsal (Figura 13, n. $\left.{ }^{\text {os }} 3-4\right)$.

Se puede constatar por tanto un abandono progresivo de un utillaje de caza aparentemente "perfecto" desde el punto de vista balístico (De la Rasilla y Santamaría, 2005-2006) y su substitución por otro tipo de utillaje con menor dificultad de producción, mayor facilidad para su reemplazamiento o reparación, aunque probablemente también una menor efectividad desde un punto de vista balístico. Las razones para una trasformación de esta naturaleza debieron ser importantes. Se ha planteado que pudo estar relacionada con cambios ambientales, por ejemplo, cambios en la abundancia de los distintos tipos de presas (Straus, 1990; ver ejemplos etnográficos en Pétrequin y Pétrequin, 1991); sin embargo, observamos una falta de correlación entre los tipos de presas cazadas y el tipo de armamento recuperado. Como ejemplos de esto último podemos señalar los casos de Arlanpe, Amalda o El Pendo, con porcentajes muy similares de laminillas de dorso y puntas foliáceas, y sin embargo grandes diferencias en los tipos de presa, siendo mayoritarias en los dos primeros las especies de roquedo (Altuna et al., 1990) y el ciervo en El Pendo (Castaños, 2001). Otro ejemplo sería el de la cueva de La Riera, en la que las fluctuaciones en los tipos de armas a lo largo de la secuencia no vienen acompañadas de cambios importantes en los tipos de presa. Un último ejemplo sería el de Chufín, en el que en el nivel A se cazan mayoritariamente animales de roquedo (Quesada, 1997), siendo la proporción de puntas foliáceas sensiblemente superior a la de las laminillas de dorso (Cabrera, 1977).

Este cambio podría estar relacionado también con una intensificación en la caza, motivada por una mayor dificultad en la obtención de presas, un aumento de las necesidades subsistenciales o cambios estructurales en la forma en la que se redistribuyen alimentos y otros recursos dentro del grupo. En este contexto un utillaje de menor coste y mayor facilidad de fabricación permitiría un aumento significativo en el número de intentos de caza, lo que favorecería mejorar la ratio 
coste/recompensa a pesar de que la efectividad de cada intento fuese menor. Esta intensificación podría estar también informándonos de un cambio en la división social del trabajo, con la apertura de las actividades de caza a un segmento mayor de la población. En cualquier caso se observa, además de un cambio tecnológico, un cambio en el significado social de las armas, en el que las puntas -o su fabricación- dejan de ser un elemento tan importante de diferenciación social entre individuos o de colectivos dentro del grupo. Es interesante notar como durante el Solutrense se observa una gran parquedad de otros elementos de diferenciación como el arte mueble, los ornamentos o la industria ósea decorada, coincidiendo con la multiplicación de elementos foliáceos de una alta tecnicidad, frecuentemente realizados en materias primas exógenas, etc. Por el contrario, en el Magdaleniense inferior se generalizan (González Sainz, 2005) todas esas manifestaciones al tiempo que desaparecen utillajes líticos "costosos" como las puntas foliáceas. Puede que ambos elementos no estén relacionados de manera más que coyuntural, pero resulta atractiva la hipótesis de que esta transformación en el utillaje de caza sea un síntoma de una transformación social más profunda.

\section{Conclusiones}

Los resultados del análisis del nivel II de Arlanpe proporcionan nueva información acerca de la organización territorial, económica y social al final del Solutrense. Las estrategias de aprovisionamiento tecnológico tanto de utillaje de sílex como de hueso, la naturaleza y función de estos útiles, el espectro faunístico representado y las otras evidencias de actividad detectadas en este nivel, como los hogares, indican que Arlanpe es una ocupación compleja cuya función está principalmente relacionada con la preparación de partidas de caza, pero en la que se realizan además otras tareas de tipo doméstico. Esta ocupación se inserta en una zona intermedia dentro de un eje de explotación del territorio que abarca desde la costa hasta la Llanada Alavesa, lo cual evidencia que las estrategias de explotación territorial muestran también una variación respecto al modelo defendido para otras áreas geográficas como el valle del Asón (Straus y González Morales, 2009).

Las ocupaciones solutrenses de Arlanpe, datadas en torno a 17100 uncal. BP, presentan características tecnológicas y tipológicas que son coherentes con una atribución al Solutrense superior final cantábrico. Como hemos planteado en la discusión, la atribución de los conjuntos datados entre 18 y 17000 uncal. BP a un Magdaleniense inicial o arcaico nos parece que no se corresponde con la realidad arqueológica cantábrica. De hecho, entendemos que el final del Solutrense superior, presente en un número cada vez más importante de secuencias, representa un fenómeno complejo, con gran variedad de situaciones, en el que se puede leer una transformación local desde el Solutrense al Magdaleniense inicial (Straus y González Morales, 2007).

Hemos planteado asimismo, a modo de hipótesis, que parte de las causas de este cambio habría que buscarlas en la transformación de las relaciones sociales, intra- e intergrupales, lo que influiría a su vez en la elección de nuevos modelos de gestión territorial y en la transformación de los sistemas tecnológicos. No obstante, creemos que el estado de conocimientos sobre el final del Solutrense es aún demasiado precario para poder abordar de manera sólida estas cuestiones. En este sentido el aporte de estudios interdisciplinares como el que hemos presentado de Arlanpe parece un camino a seguir en los próximos años.

\section{Bibliografía}

Altuna, J. (1972): Fauna de mamiferos de los yacimientos prehistóricos de Guipúzcoa. Munibe, vol. XXIV. San Sebastián: Sociedad de Ciencias Aranzadi.

Altuna, J.; Baldeón, A. y Mariezkurrena, K. (1990): La cueva de Amalda (Zestoa, País Vasco). Ocupaciones paleoliticas y postpaleoliticas. San Sebastián: Eusko Ikaskuntza.

Aura, J. E.; Tiffangom, M.; Jordá Pardo, J. F.: Duarte, E.; Fernández de la Vega, J.; SantamaRÍA, D.; DE la Rasilla, M.; Vadillo, M. y Pérez Ripoll, M. (2012): "The Solutrean-Magdalenian transition: A view from Iberia", Quatenary International, 1-13. (doi:10.1016/j.quaint.2012.05.020).

BALDEÓN, A. (1990): "La industria lítica de los niveles paleolíticos". En Altuna, J.; Baldeón, A. y 
Mariezkurrena, K. (eds.): La cueva de Amalda (Zestoa, País Vasco). Ocupaciones paleoliticas y postpaleoliticas. San Sebastián: Eusko Ikaskuntza, pp. 63-115.

Barandiarán, I. (1967): Paleomesolítico del Pirineo Occidental. Bases para la sistematización tipológica del instrumental óseo paleolitico. Monografías Arqueológicas. Zaragoza: Univ. de Zaragoza.

BORDES, J.-G. (2006): "News from the West: a reevaluation of the classical Aurignacian sequence of the Périgord". En Bar-Yosef, O. y ZilhÃo, J. (eds.): Towards a definition of the Aurignacian. Proceedings of the Symposium held in Lisbon, Portugal, June 2530, 2002. Trabalhos de Arqueologia, 45. Lisboa: American School of Prehistoric Research/Instituto Português de Arqueología, pp. 147-171.

Bosselin, B. y Djindjian, F. (1999): "Une révision de la séquence de la Riera (Asturies) et la question du Badegoulien cantabrique", Bulletin de la Société Préhistorique Française, 96 (2), pp. 153-173. http://dx.doi.org/10.3406/bspf.1999.10939

Brochier, J. É. (2008): "Plus c'est long, plus c'est large... mais encore ? Sur quelques caractères métriques des lames de plein débitage". En BroChier, J. É.; Guilcher, A. y Pagni, M. (eds.): Mélanges offerts à Gaétan Congès et Gérard Sauzade, Archéologies de Provence et d'ailleurs. Bulletin Archéologique de Provence, supplément n. ${ }^{\circ}$ 5, pp. 75-86.

CABrera, V. (1977): "El yacimiento solutrense de Cueva Chufín (Riclones, Santander)". En Actas del XIV Congreso de Arqueología Peninsular. Zaragoza: Secretaría General de los Congresos Arqueológicos Nacionales, vol. I, pp. 157-164.

CAstaños, P. (2001): "Estudio de la fauna del nivel 4 del denominado 'corte solutrense de Carballo"'. En Montes, R. y SAnguino, J. (eds.): La cueva de "El Pendo": actuaciones arqueológicas 1994-2000. Santander: Consejería de Cultura, Educación y Deporte, Gobierno de Cantabria, pp. 153-160.

Chauvin, A. (2012): Tecnología litica de los cazadoresrecolectores del final del Pleistoceno: la producción y transformación de los soportes en La Garma A (Cantabria, España) entre 15.000 y 12.000 cal BC. BAR Snt. Ser., 2336. Oxford: Archaeopress.

Corchón, M. S. (1990): "La cueva de Las Caldas (Prionio, Oviedo)". Investigaciones efectuadas entre 1980 y 1986". En Excavaciones Arqueológicas en Asturias 1980-1986. Oviedo, pp. 37-53.

- (1999): "Solutrense y Magdaleniense del oeste de la Cornisa Cantábrica: dataciones 14C (calibradas) y marco cronológico", Zephyrus, LII, pp. 3-32.

CORCHÓN, M. S. y GARRIDO, D. (2007a): "Labores de mantenimiento y uso identificadas en las agujas de la cueva de Las Caldas", Zephyrus, LX, pp. 79-97.
- (2007b): "La manufactura de agujas durante el Magdaleniense. El modelo de la Cueva de Las Caldas (Priorio, Oviedo, Asturias)". En Ramos, M. L.; GonzÁlez, J. E. y BAena, J. (eds.): Arqueología experimental en la Peninsula Ibérica: Investigación, didáctica y patrimonio. Santander: Asociación Espańola de Arqueología Experimental, pp. 213-223.

De la Rasilla, M. (1996): "El Solutrense y Magdaleniense en la Región Cantábrica", Gallaecia, 14-15, pp. 103-111.

De la Rasilla, M. y Santamaría, D. (2005/2006): "Tecnicidad y Territorio: Las puntas de base cóncava del Solutrense cantábrico", Munibe (Antropologia-Arkeologia), 57, pp. 149-158.

De la Rasilla, M. y STRaus, L. G. (2004): "El poblamiento en la región Cantábrica en torno al Último Máximo Glacial: Gravetiense y Solutrense”. En Fano, M. A. (ed.): Las sociedades del Paleolítico en la Región Cantábrica. Bilbao: Bizkaiko Foru Aldundia-Diput. Foral de Bizkaia, pp. 209-242.

DuCASSE, S. y LANGlais, M. (2007): "Entre Badegoulien et Magdalénien, nos cours balancent... Approche critique des industries lithiques du Sud de la France et du Nord-Est espagnol entre 1900 et 16500 Bр", Bulletin de la Société Préhistorique Française, 104 (4), pp. 771-785. http://dx.doi.org/10.3406/bspf.2007.13622

Esparza, X. y MujiKa, A. (1999): "Reflexiones en torno a la estratigrafía de Ermittia (Deva. Gipuzkoa)". En XXIV Congreso Nacional de Arqueología. Vol. I. Los problemas del Paleolitico Superior en el ámbito mediterráneo peninsular. Murcia: Gobierno de la Región de Murcia, Instituto de Patrimonio Histórico, pp. 61-69.

Fortea, J.; De la Rasilla, M.; Santamaría, D.; Martínez, L.; Duarte, E. y Fernández, J. (2010): "El Paleolítico superior en Asturias en los albores del siglo XXI". En MANGADO, X. (ed.): $E l$ Paleolitico superior peninsular. Novedades del siglo XXI. Barcelona: Univ. de Barcelona, pp. 271-290.

Garate, D. (2012): Neandertales y Cromañones. Los primeros pobladores de Bizkaia. Guías del Arkeologi Museoa, n. ${ }^{\circ}$ 2. Bilbao: Diputación Foral de Bizkaia, Bizkaikoa y Arkeologi Museoa.

Garate, D. y Rios-Garaizar, J. (2012): La cueva de Askondo (Mañaria, Bizkaia). Arte parietal y ocupación humana durante la prehistoria. Kobie, serie BAI, 2. Bilbao: Diputación Foral de Bizkaia.

GARRIDO, D. (2008): "Actividades técnicas identificadas en la superficie del instrumental óseo durante el Paleolítico superior cantábrico", Sautuola, 14, pp. 75-94.

GonZÁlez EChegaray, J. y Freeman, L. G. (1978): Vida y muerte en Cueva Morín. Santander: Institución Cultural de Cantabria. 
GonZÁlez SÁINZ, C. (2005): “Actividad gráfica Magdaleniense en la región Cantábrica. Datación y modificaciones iconográficas". En BICHO, N. F. y CorChón, M. S. (eds.): Actas do IV Congreso de Arqueologia Peninsular. Faro, 14 a 19 Setembro de 2004. Faro: Centro de Estudios de Patrimonio, Departamento de Historia, Arqueologia e Patrimonio, Universidade do Algarve, pp. 157-181.

Gutiérrez, E.; Hierro, J. A.; Rios-Garaizar, J.; Garate, D.; Gómez, A. y ArCeredillo-Alonso, D. (2012): "El uso de la cueva de Arlanpe (Bizkaia) en época tardorromana", Archivo Español de Arqueología, 85, pp. 211-233.

Hammer, Ø.; Harper, D. A. T. y RYan, P. D. (2001): "PAST: Paleontological Statistics Software Package for Education and Data Analysis", Palaeontologia Electronica, 4 (1), p. 9.

Monchot, H.; Mashkour, M. y Vigne, J. D. (2005): "Kernel smoothing and mixture analysis for the determination of the sex ratios at death, at the beginning of the domestication of ungulates". En Vigne, J.-D.; Peters, J. y Helmer, D. (eds.): The First Steps of Animal Domestication. New Archaeological approaches. Oxford: Oxbow Books, pp. 55-60.

MUNOZZ, E. (2001): "Los materiales líticos del nivel 4 del denominado 'corte solutrense de Carballo". En Montes, R. y SAnguino, J. (eds.): La cueva de "El Pendo": actuaciones arqueológicas 1994-2000. Santander: Consejería de Cultura, Educación y Deporte, Gobierno de Cantabria, pp. 141-152.

Muñoz, E. y Serna, A. (1999): "Los niveles solutrenses de la Cueva del Ruso I (Igollo de Camargo, Cantabria)", Sautuola, 6, pp. 161-176.

Petrequin, A.-M. y Petrequin, P. (1990): "Flèches de chasse, flèches de guerre, le cas des Danis d'Irian Jaya (Indonésie)", Bulletin de la Société Préhistorique Française, 87 (10-12), pp. 484-511.

http://dx.doi.org/10.3406/bspf.1990.9931

QuesadA, J. M. (1997): "La caza en el Solutrense cantábrico: una nueva perspectiva", Zephyrus, 50, pp. 3-36.

Reimer, P. J.; Baillie, M. G. L.; Bard, E.; Bayliss, A.; Beck, J. W.; BlackWell, P. G.; Bronk RamSEY, C.; Buck, C. E.; Burr, G. S.; Edwards, R. L.; Friedrich, M.; Grootes, P. M.; GuILderson, T. P.; Hajdas, I.; Heaton, T. J.; Hogg, A. G.; Hughen, K. A.; Kaiser, K. F.; Kromer, B.; McCormac, F. G.; Manning, S. W.; Reimer, R. W.; Richards, D. A.; Southon, J. R.; Talamo, S.; Turney, C. S. M.; Van der Plicht, J. y WeyHENMEYER, C. E. (2009): "IntCal09 and Marine09 radiocarbon age calibration curves, 0-50,000 years cal BP", Radiocarbon, 51 (4), pp. 1111-1150.
Rios-Garaizar, J.; Garate, D.; Gómez-Olivencia, A.; Iriarte-Avilés, E.; Aranburu-Artano, A.; Arceredillo-Alonso, D.; García, A.; IriarteChiapusso, M. J.; Moreno, J.; Murelaga, X.; Ortiz, J. E.; Torres, T.; San Pedro-Calleja, Z. y Zapata-PeŃa, L. (2011): "The Lower to Middle Palaeolithic transition in northern Iberia: new data from Arlanpe Cave", Antiquity, 85 (329).

Rios-Garaizar, J.; Iriarte-Avilés, E.; Gárate, D.; Gómez-Olivencia, A. y San Pedro, Z. (2008): "Nuevos datos sobre la transición entre el Solutrense Superior y el Magdaleniense inferior en la Región cantábrica: la cueva de Arlanpe (Lemoa, Bizkaia)", Sautuola, 14, pp. 95-104.

Straus, L. G. (1974): "Le solutréen du Pays Basque Espagnol: Une esquisse des données", Munibe, 26 (3-4), pp. 173-181.

- (1990): "The Original Arms Race: Iberian Perspectives on the Solutrean Phenomenon". En KOZLOWSKI, J. (ed.): Feuilles de Pierre. Liège: ERAUL, pp. 425-447.

Straus, L. G. y Clark, G. A. (1986): La Riera Cave. Stone Age Hunter-Gatherer Adaptations in Northern Spain. Tempe: Arizona State University.

- (2000): "La grotte de la Riera (Asturies) et la question du Solutréen Cantabrique (et Iberique)", Bulletin de la Société Préhistorique Française, 97 (1), pp. 129-132. http://dx.doi.org/10.3406/bspf.2000.11065

Straus, L. G. y González Morales, M. R. (2007): "Further Radiocarbon Dates for the Upper Paleolithic of El Mirón Cave (Ramales de la Victoria, Cantabria, Spain)", Radiocarbon, 49 (3), pp. 1205-1214.

- (2009): "A preliminary description of Solutrean occupations in El Mirón cave (Ramales de la Victoria, Cantabria)", Munibe (Antropologia-Arkeologia), 60, pp. 117-137.

Straus, L. G.; González Morales, M. R.; GutiéRREZ Zugasti, I. e Iriarte, M. J. (2011): Further Solutrean evidence in El Mirón Cave (Ramales de la Victoria, Cantabria)", Munibe (AntropologiaArkeologia), 62, pp. 117-133.

Straus, L. G.; González Morales, M. R. y STEWART, E. B. (2008): "Early Magdalenian Variability: New Evidence from El Mirón Cave, Cantabria, Spain”, Journal of Field Archaeology, 33 (2), pp. 197-218. http://dx.doi.org/10.1179/009346908791071321

TARriño, A. (2006): El sílex en la cuenca Vasco-Cantábrica y Pirineo Navarro. Madrid: Ministerio de Cultura.

YraVedra, J. (2002): "Especialización o diversificación. Una nueva propuesta para el Solutrense y el Magdaleniense Cantábrico", Munibe (AntropologiaArkeologia), 54, pp. 3-20. 